\title{
10
}

\section{Toward SME 4.0: The Impact of Industry 4.0 Technologies on SMEs' Business Models}

\author{
Philipp C. Sauer, Guido Orzes, and Laura Davi
}

\subsection{Introduction}

Industry 4.0 (I4.0) represents a radical change in firms' operations that is particularly challenging for small- and medium-sized enterprises (SMEs) due to the substantial need for capital and knowledge (Müller and Däschle 2018; Orzes et al. 2020). Nevertheless, I4.0 and the technologies subsumed below this concept promise to enhance the productivity, flexibility, and competitiveness of SMEs (Kagermann et al. 2013; Weking et al. 2019). To realize such a far-reaching change in an economically sustainable way I4.0 implementation should ideally be complemented

P. C. Sauer $(\bowtie) \cdot$ G. Orzes $\cdot$ L. Davi

Industrial Engineering and Automation (IEA), Faculty of Science and Technology, Free University of Bozen-Bolzano, Bolzano, Italy e-mail: philippchristopher.sauer@unibz.it

G. Orzes

e-mail: guido.orzes@unibz.it

L. Davi

e-mail: laura.davi@natec.unibz.it 
by a modification in the Business Model (BM) of the firm, i.e., the firm's logic of creating and capturing value (Zott and Amit 2010). Moreover, the I4.0 concept and the underlying technologies are constantly innovated (Kagermann et al. 2013; Culot et al. 2020) thus requiring a corresponding continuous evaluation of BMs that enable its implementation and sustained viability (Müller and Däschle 2018).

While this need is widely acknowledged in literature, it is hindered by the substantially different nature of the concepts of I4.0, originating from the engineering domain, and BMs, originating from the business strategy domain. Extant definitions of I4.0 technologies (see Culot et al. 2020 for an extensive review) and of BMs reveal indeed a wide range of underlying elements that need to be considered. However, there is still no uniform "recipe" of technology to BM element interrelations. Due to the limited availability of resources of SMEs, the majority of them struggles to build and maintain sufficient expertise in both fields that are required to simultaneously modify both the operations and BM (Müller and Däschle 2018). Nevertheless, SMEs build the backbone of an economy and represent even in the highly industrialized European Union 99\% of all businesses (European Commission 2020).

This chapter aims therefore to investigate the interrelation between I4.0 technologies and BMs with a specific focus on SMEs. In detail, the addressed research question is: How can the implementation of Industry 4.0 technologies drive the modification of the business models of small-and medium-sized enterprises? To answer this question, a combined approach relying on literature and on web-based secondary data is applied. This enables to take stock of the current literature to identify hotspots and gaps in the academic investigation of the interrelation of I4.0 technologies and BMs in SMEs. Subsequently, this will be complemented by an empirical investigation of 30 SMEs websites to validate the literature-based findings.

The chapter is organized as follows: Sect. 10.2 introduces the theoretical background for the study consisting of the concepts of I4.0, BM and SMEs. Section 10.3 presents the applied methodology and Sect. 10.4 summarizes the results. Finally, Sect. 10.5 presents the discussion and conclusion of the study including the contributions to research and practice, its limitations, and the derived research directions. 


\subsection{Background}

In this section, we present three concepts that are of particular relevance for our study: I4.0 technologies (Sect. 10.2.1), BMs (Sect. 10.2.2), and SMEs (Sect. 10.2.3).

\subsubsection{Industry 4.0}

The term "Industrie 4.0" was first coined in 2011 to strengthen the competitiveness of the German industry and since then diffused (with some adaptations) all over the world (Tirabeni et al. 2019). In its core, I4.0 represents a synonym for the Fourth Industrial Revolution that has been preceded by other fundamental steps such as taking advantage of mechanical innovations like the steam power, cotton spinning, and railroads (First Industrial Revolution), allowing mass production through assembly lines and electricity (Second Industrial Revolution), and automating production lines by using electronic systems and computer technologies (Third Industrial Revolution) (Ingaldi and Ulewicz 2020).

Starting from this basis, I4.0 "describes the increasing digitization and automation of the manufacturing environment, as well as the creation of digital value chains to enable communication between products, their environment and business partners" (Lasi et al. 2014, p. 240). Similarly, I4.0 can be defined as "a collective term for technologies and concepts of value chain organization" (Ślusarczyk 2018, p. 234). Moreover, the distinction between industry and services becomes less relevant as digital technologies are connected with industrial products and services forming hybrid products which are neither exclusively goods nor services (Strandhagen et al. 2017).

The main features of I 4.0 are related to integration, real-time operability, flexibility, servitization, customer orientation, and expertization that facilitate the connection and communication between humans and machines through the Internet of Things and Cyber-Physical Systems (Hermann et al. 2016). As a result, products become customized, processes are networked, and knowledge barriers are reduced among 
users. The "context-aware" Smart Factory takes into consideration the position as well as status of a product within the process and assists machines as well as people performing their tasks (Rejikumar et al. 2019; Weking et al. 2019).

Consequently, I4.0 arises from its elementary technologies, which lay the foundation for the integration of intelligent machines, humans, physical objects, production lines, and processes to form a new kind of value chain across organizational boundaries, featuring intelligent, networked, and agile production (Alcácer and Cruz-Machado 2019). Resulting from the described breadth of the concept and its rapid development, there is an increasing and steadily changing range of technologies that form the entirety of I4.0.

In our study, we consider a set of technologies that form the core of I4.0 and build the basis for the majority of today's I4.0 technology development and application. Adopting such an established and focused set of core technologies enables a high validity and generalizability of the analysis. The considered technologies are drawn from a widely adopted and highly cited Boston Consulting Group report on I4.0 technology (Rüssmann et al. 2015) and a very recent and more academic operationalization of it proposed by Culot et al. (2020) based on a systematic review on I4.0 definitions: Internet of Things, Cyber-Physical Systems, Visualization technologies (among which Augmented Reality), Cloud Computing, Cybersecurity, Blockchain Technology, Simulation and Modelling, Machine Learning and Artificial Intelligence, Big Data Analytics, Additive Manufacturing systems (among which 3D-Printing), and Advanced Robotics.

These core technologies of I4.0 are defined in the following, also to establish enhanced traceability and reliability for the subsequent analysis. Moreover, all I4.0 technologies are written in capital letters in the remainder of the chapter to facilitate their recognition in the text.

Internet of Things (IoT) refers to physical objects connected through the Internet. These (smart) objects have their own intelligence, can collect information, interact with the surrounding environment, connect to one another, exchange data in real time, and trigger actions through the Internet. Therefore, IoT connects people and things anytime, 
anyplace, with anything and anyone, based on any network and any service (e.g., Weking et al. 2019).

Cyber-Physical Systems (CPS) express the interconnection between physical and virtual environments. CPS integrate, control, and coordinate operations and processes while simultaneously providing and using data-accessing and data-processing services. Integrating CPS within production, logistics, and services enables a connection across all levels of production between autonomous and cooperative elements across the entire supply chain (e.g., Rejikumar et al. 2019).

Visualization Technologies, such as Augmented Reality (AR) and Virtual Reality (VR), enhance the perception of the physical world through visual elements. Visual tools provide a virtual representation of entire (production) systems and their interactions within the supply chain. This enables a transformation of how enterprises serve customers, train employees, design, and create products (e.g., Brenner 2018; Dallasega et al. 2020).

Cloud Computing (CC) includes data storage, servers, databases, networking, and software that enable remote information access on a virtual space. This cloud can connect different entities, which is reflected in its four main types of access: public; private within the same (meta)organization; hybrid, if public and private clouds are combined; and community, shared by multiple organizations and supported by common interests and concerns (e.g., Armbrust et al. 2010).

Cybersecurity aims to protect private information applied to hardware and software to avoid the misuse of data and devices. Cybersecurity relies on protecting, detecting, and responding to attacks. It has become essential since virtual environments, remote access, and stored data on cloud systems represent increasing vulnerabilities (e.g., Kotarba 2018).

Blockchain Technology is based on decentralizing the storage of data to prevent such data to be owned, controlled, or manipulated by a central actor, thus enabling the immutability and integrity of data across several distributed nodes that are linked in a peer-to-peer network. It is expected to change the way in which ownership, privacy, uncertainty, and collaboration are conceived in the digital world (e.g., Ahram et al. 2017). 
Simulation and Modelling facilitate the validation of products, processes, or system design and configuration. Furthermore, they enable cost reduction and increased product quality, while reducing development time, designing and engineering errors, and wastes (e.g., Alcácer and Cruz-Machado 2019).

Machine Learning (ML) and Artificial Intelligence (AI) refer to the simulation of human intelligence in machines that mimic human thinking and actions. ML is in fact a sub-field of AI expressing the idea that a computer program can learn and adapt based on data without human interference (e.g., Matthyssens 2019).

Big Data Analytics describes the acquisition of large and complex data sets from different sources and at different times. It includes the collection, storage, and sharing of data and their analysis and evaluation. Big Data can be defined as "large volumes of high velocity, complex and variable data that require advanced techniques and technologies to enable the capture, storage, distribution, management, and analysis of the information" (Mills et al. 2012, p.10). This enables, among other advantages, predictive maintenance and real-time decision-making (e.g., Pisano et al. 2015).

Additive Manufacturing (AM), often simplified as 3D-Printing, is a technology creating three-dimensional components and products directly from raw materials, layer upon layer. It accelerates prototyping in manufacturing and ensures design and product testing, improves creativity in shapes as well as geometry, and allows improved personalization (e.g., Kamble et al. 2018).

Advanced Robotics such as autonomous and collaborative robots interact with one another and are able to work safely with humans in the same workspace (e.g., Kumar 2018).

Besides these technologies, New Materials and Energy Management Solutions are becoming more and more entwined with the I4.0 concept. A wide range of miniaturized devices that are essential to I4.0 rely indeed on minerals that are criticized for sustainability problems in their production and supply chains (Hiete et al. 2019). These "old" materials will eventually be replaced by substitutes or "new" material currently being developed. In the meantime, such materials are just like the use of energy subject to standardization and management frameworks (Jacob et al. 
2019) that aim to control the negative sustainability impact of I4.0 implementation and could drive its success by gradually lowering this downside of the Fourth Industrial Revolution.

\subsubsection{Business Model}

A BM is "the basic logic of a company that describes what benefits are provided to customers and partners [...] and how the provided benefits flow back into the company in the form of revenue" (Schallmo et al. 2017, p. 5). The BM consists of a set of interdependent organizational activities through which human, physical, and/or capital resources are brought together in order to achieve the enterprise's goals (Zott and Amit 2010).

Despite the absence of a unanimous definition, it is widely accepted that a BM reveals how a firm creates, delivers, and captures value. It provides a framework of costs, payments, and revenues together with the company's strategies, ranging from the products or services it offers to how it differentiates from competitors and how it integrates with its partners in the value chain. As a result, " a good business model yields value propositions that are compelling to customers, achieves advantageous cost and risk structures, and enables significant value capture by the business that generates and delivers products and services" (Teece 2010, p. 174).

Osterwalder et al. (2005, p. 17) formalized a BM as a "conceptual tool that contains a set of elements and their relationships and allows expressing the business logic of a specific firm. It is a description of the value a company offers to one or several segments of customers and of the architecture of the firm and its network of partners for creating, marketing, and delivering this value and relationship capital, to generate profitable and sustainable revenue streams."

Despite the advantages of a well-designed BM, the development and innovation of a BM require substantial expertise and resources causing especially SMEs to struggle with these tasks (Müller et al. 2018). This is also caused by the interrelatedness of the various BM elements, for which previous research found that a change in one BM block likely impacts the other blocks as well (Spieth and Schneider 2016). Moreover, it has been found that changes in the BM can cause drifts in a firm's mission that 
ultimately results in inconsistent action of the firm with its originally stated mission (Klein et al. 2020). In effect, it has been found that the BM needs to be closely aligned with the firm's orientation to economic, social, and environmental sustainability (e.g., Hahn et al. 2018; Klein et al. 2020). Moreover, changes in a BM can severely affect the customers' brand perceptions such as brand trust, brand loyalty, and brand equity (Spieth et al. 2019).

At the intersection of BMs and I4.0, a recent study by Weking et al. (2019) found a substantial lack of research. Based on 32 cases described in literature, the authors identify three super-patterns of I4.0 business models that are (a) integration, (b) servitization, and (c) expertization. While Weking et al. (2019) analyzed the I4.0 BM in general, they also find that the relationship of I4.0 BMs and I4.0 technologies is underresearched (see also Rayna and Striukova 2016). This particularly applies to SMEs, for which an investigation regarding the implementation of BM adoptions over time should be considered (Müller 2019).

The Canvas model proposed by Osterwalder and Pigneur (2010) highlights the following BM building blocks and related definitions. By using the Canvas model, we again adopt a widely used on wellestablished framework for the analysis to match the high generalizability and validity of the I4.0 technologies. Moreover, all BM building blocks are written in capital letters in the remainder of the chapter to facilitate their recognition in the text.

Customer Segments are the different groups of individuals or parties that a firm wants to reach and satisfy. The question that the company should ask itself for this block is "Who are we creating value for? Who are our most important customers?" (ibid., p. 21). The target market can be a mass, a niche, and/or a segmented market.

Value Propositions define which products and services create value for a given Customer Segment. The relevant questions in this case are: "What value do we deliver to our customers? To which customers' needs are we going to respond?" (ibid., p. 23). Each Value Proposition is made up of a specific bundle of goods and/or services peculiar to a Customer Segment. Related values may be quantitative, such as efficiency, or qualitative, such as design (ibid.). 
Channels illustrate the way in which the Customer Segments are reached to deliver the appropriate Value Proposition. The right balance of Channels used to satisfy customers' expectations is essential in bringing a Value Proposition to the market. The questions for this building block are: "Through which Channels do our Customer Segments want to be reached? How are we reaching them now? Which ones are most cost-efficient?" (ibid., p. 27).

Customer Relationships express the relationships between a firm and a specific Customer Segment. These relationships range from personal to automated ones with the most typical Customer Relationships ranging from personal assistance to self-service. The relevant question is in this case "What type of relationship does each of our Customer Segments expect us to establish and maintain?" (ibid., p. 29).

Revenue Streams indicate the income generated from each Customer Segment. There are two main types of Revenue Streams: transaction revenues occurring when a product or service is sold and recurring revenues resulting from ongoing payments or fees. The fundamental questions are: "For what value are our customers really willing to pay? For what do they currently pay? How much does each Revenue Stream contribute to [the company's] overall revenues?" (ibid., p. 31).

Key Resources let a firm create and offer a Value Proposition, reach its customers, and earn revenues. Different Key Resources are needed for different BMs. In fact, they can be physical, financial, intellectual, or human. At the same time, they can be owned or leased by the company or acquired from the company's partners. The question that the company should ask itself is "What Key Resources do our Value Propositions require?" (ibid., p. 35). That is, what Key Resources are needed by the other building blocks?

Key Activities aim at creating and offering Value Propositions, reaching the different markets, and maintaining Customer Relationships. They range from production to problem-solving, or networking. The relevant question is: What key activities are fundamental for our BM? That is, what key activities are requested by the other building blocks? (ibid.).

Key Partnerships illustrate the network of suppliers and partners that enable the BM. Companies create partnerships to reduce risks or acquire 
resources. These Key Partnerships can be strategic alliances between non-competitors or competitors and buyer-supplier relationships. The questions are: "Who are our key partners [and] key suppliers? Which Key Activities do partners perform?" (ibid., p. 39).

Cost Structure indicates the most important costs after defining Key Resources, Key Activities, and Key Partnerships including costs related to creating and delivering value, maintaining Customer Relationships, and generating Revenue Streams. BM can be cost- or value-driven, though most represent a balance of the two aspects. The relevant questions are: "What are the most important costs inherent in our BM? Which Key Resources [and] Key Activities are most expensive?" (ibid., p. 41).

In line with Kotarba (2018), the BM Canvas is often adopted due to its relative simplicity which provides support for quick and efficient content documentation in the process of identifying crucial components of an organization internal structure and relationship with the ecosystem it belongs to.

\subsubsection{Small- and Medium-Sized Enterprises}

According to the European Commission (2020), SMEs are defined as firms with a maximum number of 250 employees and a maximum annual revenue of 50 million euros.

SMEs play an important role in the economic scenario since they represent $99 \%$ of the total enterprises in the European Union (European Commission 2020). According to Müller et al. (2018), SMEs contribute more than $50 \%$ of gross value added throughout Europe, but tend to struggle with both the implementation of I4.0 and BM innovations, resulting in insufficient access to external knowledge and unclear innovation strategies, which limit SMEs' efforts in making incremental improvements.

Most SMEs are family-owned and often the owner is also the manager. This may represent an advantage in terms of flexibility and readiness to react to changes due to a flat and clear organization. In fact, being settled around more informal working relationships, communications between managers and employees are quicker and more direct. This allows to 
share new concepts or innovative ideas more efficiently across the firm and to achieve a deeper engagement of employees. Moreover, SMEs' strength is to create value to the firm, which results in investing in research and development, employees' training, and life-long learning. However, SMEs' limited financial possibilities, if compared to large enterprises, may prevent them from having skilled workers and the necessary economic resources to profitably invest in new technologies, at least at an initial stage (Müller and Däschle 2018; Orzes et al. 2020). In fact, despite training a large percentage of apprentices, they find it difficult to rely on skilled personnel when it comes to specific I4.0 technologies. It seems that the sophisticated technologies require further resources as well as supporting initiatives and may need to be adopted by SMEs at later stages. Organizational changes, together with the involvement of external professionals, must also be considered by SMEs' managers to achieve new goals.

\subsection{Methodology}

To answer the research question (i.e., "How can the implementation of Industry 4.0 technologies drive the modification of the business models of small- and medium-sized enterprises?"), a multi-method approach is applied that takes stock of the currently available literature at the intersection of I4.0 and BMs as well as the information available on companies applying I4.0. While the literature review does not focus a particular firm size, the companies' analysis is exclusively studying SMEs due to their relevance outlined in Sect. 10.2.3. Both approaches are presented in this section, starting with the literature review, followed by the contingency analysis applied to the literature review results, and the secondary data analysis.

\subsubsection{Literature Review Methodology}

In line with current best practices in the field of operations management, a content analysis-based systematic literature review is conducted 
as proposed by Seuring and Gold (2012). This contains the sequential steps of (1) material collection, (2) category selection, and (3) material evaluation. Content analysis-based reviews can be applied to academic publications as is regularly done, but also to any kind of documents and written communication (Mayring 2015), such as websites (e.g., Carbone et al. 2017), industry standards (e.g., Sauer and Hiete 2020), or newspaper articles (e.g., Ancarani et al. 2015).

Step 1) material collection encompasses designing the study including specifying the research question(s), defining the search parameters as well as database(s), and obtaining the literature to be analyzed, i.e., the material. This needs to be well documented to satisfy the quality criteria of replicability (Fink 2019; Seuring and Gold 2012). For doing so, a search has been conducted on Elsevier's Scopus, one of the most acknowledged scientific databases. The search aims at finding specific keywords on I4.0 and BMs in a paper's title, abstract, and keywords. In order to select a complete and current list of keywords, it has been decided to adopt the I4.0 search terms provided by Culot et al. (2020), which we find to be exhaustive of the aspects related to I4.0, even if it does not include keywords related to single specific technologies.

Similarly, as regards BM, the term itself is used together with the related terms "business plan" and "revenue model." We acknowledge that other keywords could be relevant, but the choice made satisfied the core of this work. This was determined by adding the keywords sequentially to the search terms while monitoring the increase in papers found. Adding more synonyms to the current search string did not yield additional papers. The resulting keywords and search string are presented in Fig. 10.1 along the other details of the material collection.

Beyond the keywords, the material collection is restricted to publications in English, with a few exceptions made if an English abstract was available while the full paper was available only in German. Furthermore, following state of the art literature reviews (Sauer and Seuring 2017; Seuring and Gold 2012) the type of publication was limited to articles, reviews, editorials, and short surveys to include only peer-reviewed publications that have undergone academic quality checks. Moreover, only publications between 2011, the year of the definition of the term I4.0, 


\section{Setting the research objectives}

Research question: How can the implementation of Industry 4.0 technologies drive the modification of the business models of small- and medium-sized enterprises?

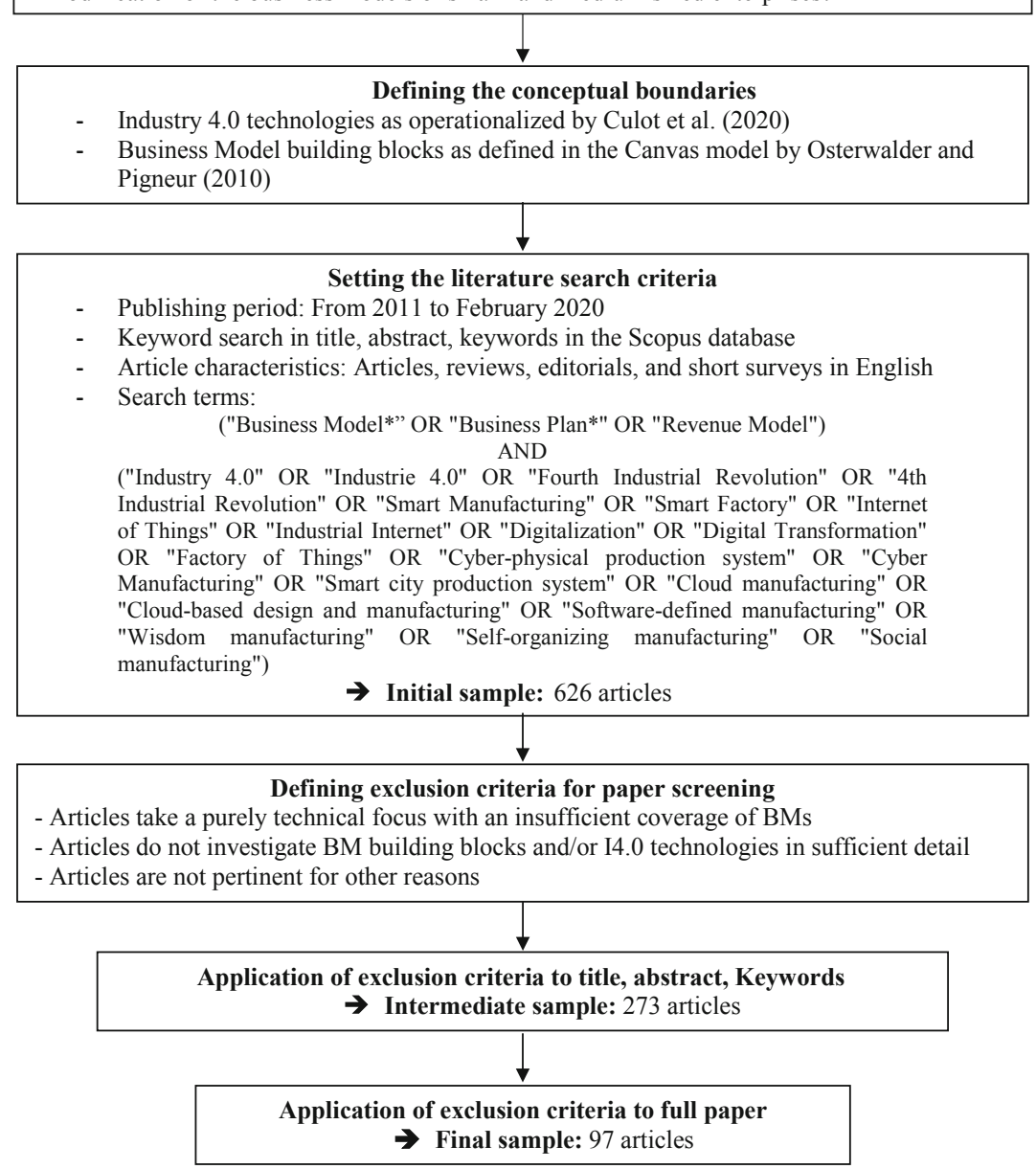

Fig. 10.1 Systematic material collection process

until February 2020 were included. This yielded an initial sample of 626 documents fitting the presented criteria.

Subsequently, the first filtering was based on the content of title and abstract as well as on its keywords (when available). This yielded an intermediate sample of 273 papers that were then checked in their full text 
against the same inclusion criteria displayed in Fig. 10.1, resulting in 97 publications fully relevant.

Step 2) category selection is critical to the validity of the review, since it defines the codes for the analysis of the selected papers (Fink 2019; Seuring and Gold 2012). Validity is established by selecting framework from well-established literature as well as highly ranked and peer-reviewed journals as suggested by Sauer and Seuring (2017). In the extant study, one framework each for the BM and I4.0 perspective are chosen that fulfill this criterion. For the BM side, we rely on the BM Canvas by Osterwalder and Pigneur (2010) and for the I4.0 side we adopted the I4.0 technologies identified by Culot et al. (2020), that have both been introduced in Sect. 10.2.

These frameworks build the basis for step 3) material evaluation, i.e., a content analysis of the selected publications (Mayring 2015) described in this paragraph and a follow-up contingency analysis presented in Sect. 10.3.2. A content analysis allows for a transparent, rule governed, and replicable application of the category system (Mayring 2015). This system is the basis for synthesizing the reviewed publication against the research questions (Seuring and Gold 2012; Mayring 2015). Seuring and Gold (2012) provided an adaption of the generic approach by Mayring (2015) to the field of operations and supply chain management. This approach is preferred against other well-known but more generic approaches such as the ones by Fink (2019) or Tranfield et al. (2003) due to the detail provided for our field. Besides the validity, content analysis is also inherently associated to the quality criterion of reliability (Mayring 2015). To ensure both, the author team defined a coding protocol and regularly discussed the coding outcomes and especially unclear cases to establish a discursive alignment of interpretation (Seuring and Gold 2012).

\subsubsection{Contingency Analysis of the Literature Review Findings}

The content analysis allows for a qualitative and quantitative analysis of the reviewed literature (Mayring 2015), which are presented separately 
in Sect. 10.4. For the quantitative investigation a contingency analysis is performed that allows to detect "association patterns between categories, i.e. [...] pairs of categories which occur relatively more frequently together in one paper than the product of their single probabilities would suggest" (Gold et al. 2010, p. 235). This detection of positive association patterns has later been extended to negative ones by Sauer and Seuring (2017). Such an analysis is based on the coding frequencies from the content analysis. The strength of the association patterns between two codes is evaluated based on the phi-coefficient that is calculated using a chi-square test. To enable this, two quality requirements need to be fulfilled to recognize valid and significant relations. First, the contingency table may not contain any expected counts below five and phi needs to be above 0.3 (Sauer and Seuring 2017).

Still, if a pattern is identified, it does not reveal the underlying causality and the use of both codes in a single paper could even be unintentional. Nevertheless, the significant associations among the codes reveal a connection that needs a literature or theory-based justification. In the end, the contingencies offer insights into the association of codes within the individual papers complementing the content analysis, that focuses on similar contents across different articles (Sauer and Seuring 2017).

Combining content and contingency analysis enables a second level of analysis and interpretation that is particularly interesting as we review a heterogeneous field. The contingencies can reveal statistically significant gaps and links within the reviewed sample. They are therefore essential for answering the research question as is done in the findings and discussion sections.

\subsubsection{Secondary Data Analysis Methodology}

In order to move beyond the literature-based evidence that has been produced from an academic perspective, the extant study furthermore includes a set of empirical data from practice. Such an approach enables a validation of the literature review results and enhances the generalizability of the findings. 
In effect, the applied method is similar to the three-step process outlined for the literature analysis in Sect. 10.3.1. The material collection was realized by analyzing nearly 150 websites of Italian industrial SMEs belonging to the Cluster "Fabbrica Intelligente" (CFI) (https:// www.fabbricaintelligente.it/). The CFI is an association including large and small- and medium-sized enterprises, as well as universities, research centers, entrepreneurs' associations, and other stakeholders, dealing with advanced manufacturing and I4.0. The association is recognized by the Italian government as a facilitator of sustainable economic growth since it develops the innovation and specialization of the Italian manufacturing sector.

Among the over 150 SMEs websites visited, 30 have been chosen since they seemed particularly significant for the goal of the research. They describe the digital transformation process of the company with reference to new technologies, together with the enhancement of specific competences and innovative BMs. Other inclusion criteria have considered the pertinence of the information present on the websites as far as the research goal was concerned. The most interesting websites resulted to be those where videos and articles contributed to the completeness of the presentation of the firm itself.

To summarize step 1) material collection, Appendix I lists and characterizes the 30 sample SMEs, indicating them with a progressive number following the alphabetical order and regardless the company's relevance. This number is used to reference the samples' SMEs in the findings section.

Step 2) category selection and the procedure of step 3) material analysis are identical to the literature review part. This is also consistent with the aim to validate the literature-based findings that are presented in the subsequent section. 


\subsection{Results}

\subsubsection{Content Analysis of the Reviewed Papers}

\subsubsection{Overarching Trends in the Reviewed Papers}

The review reveals four overarching trends that transcend the single BM blocks and I4.0 technologies:

First, I4.0 is still a developing concept, in particular for SMEs, that affects the strategies and operations of businesses, as well as the relationships between enterprises, customers, and suppliers (see also Ingaldi and Ulewicz 2020).

Second, I4.0 does not concern only manufacturing industries; it is rather about the ways in which digital technologies are brought together and, specifically, how organizations can harness them to drive competitive BMs, market, and sustainable growth. This is underlined by the fact that the papers analyzed in the literature review often regard both manufacturing industries and consulting services companies. The distinction between manufactured goods and services is becoming more and more subtle, since products and their functionalities are offered as services, and products themselves are associated to the services they deliver (see also Porter and Heppelmann 2014). This creates hybrid products which are neither exclusively goods nor services.

Third, Big Data gathering and analysis is a critical issue debated in almost $60 \%$ of the reviewed literature. Making adequate sense of Big Data means interpreting it, getting insights that lead to better decisions and strategic moves. However, apart from questions related to the expertise required to understand and correctly use this data, there are other concerns about its security. Even if the technologies Big Data and Cybersecurity should be treated as going on hand-in-hand, the latter is much less frequently found in literature, as just less than $20 \%$ of the sample papers mention it.

Fourth, the exploitation of I4.0 technologies requires, besides significant investments, a transformation in corporate structure and culture, which have to become open-minded and flexible. Collaborative environments and systematic discussions to innovate established routines 
are also/equally necessary (Tirabeni et al. 2019). Companies require resources and knowledge from different fields that do not necessarily belong to a single industry. Therefore, relationships must be built within and across industries (Ghanbari et al. 2017). This is particularly true for SMEs, for which an investigation regarding the implementation of BM adoptions over time should be considered (Müller 2019).

\subsubsection{Business Model Building Blocks Modified by Industry 4.0 Implementation}

How do new technologies support this change? Table 10.1 provides an overview of the frequency with which the nine BM building blocks appear in the literature review and some literature-based examples of how I4.0 technologies may influence them.

Among the different building blocks, which are however strictly connected and linked to one another, Customer Relationship and Key Activities are the most frequently cited (both over 70\%) by the reviewed papers. This is not surprising since collaborative engagement of customers, namely in the process of co-design, co-engineering, and co-development of products and services is an essential feature for smart factories. As a result of this co-creation process, individual products can be realized thanks for example to Simulation and Modelling. This allows to understand and satisfy customers' needs (Kagermann et al. 2013). In the case of consulting services companies, analyzing customers' data becomes a Key Activity, while manufacturing firms offer product tracking and predictive maintenance thanks to real-time monitoring and automated data analysis (Weking et al. 2019), through IoT, CPS, and Blockchain Technology.

At the same time, many I4.0 technologies, such as Additive Manufacturing, Advanced Robotics, and Visualization Technologies, just to mention a few, enhance flexibility and mass customization capabilities, contributing to a firm's Value Proposition. Together with flexibility, modularity enables a company's adaptation to the changing conditions and prerequisites of different customers' goals/requests/demands. 


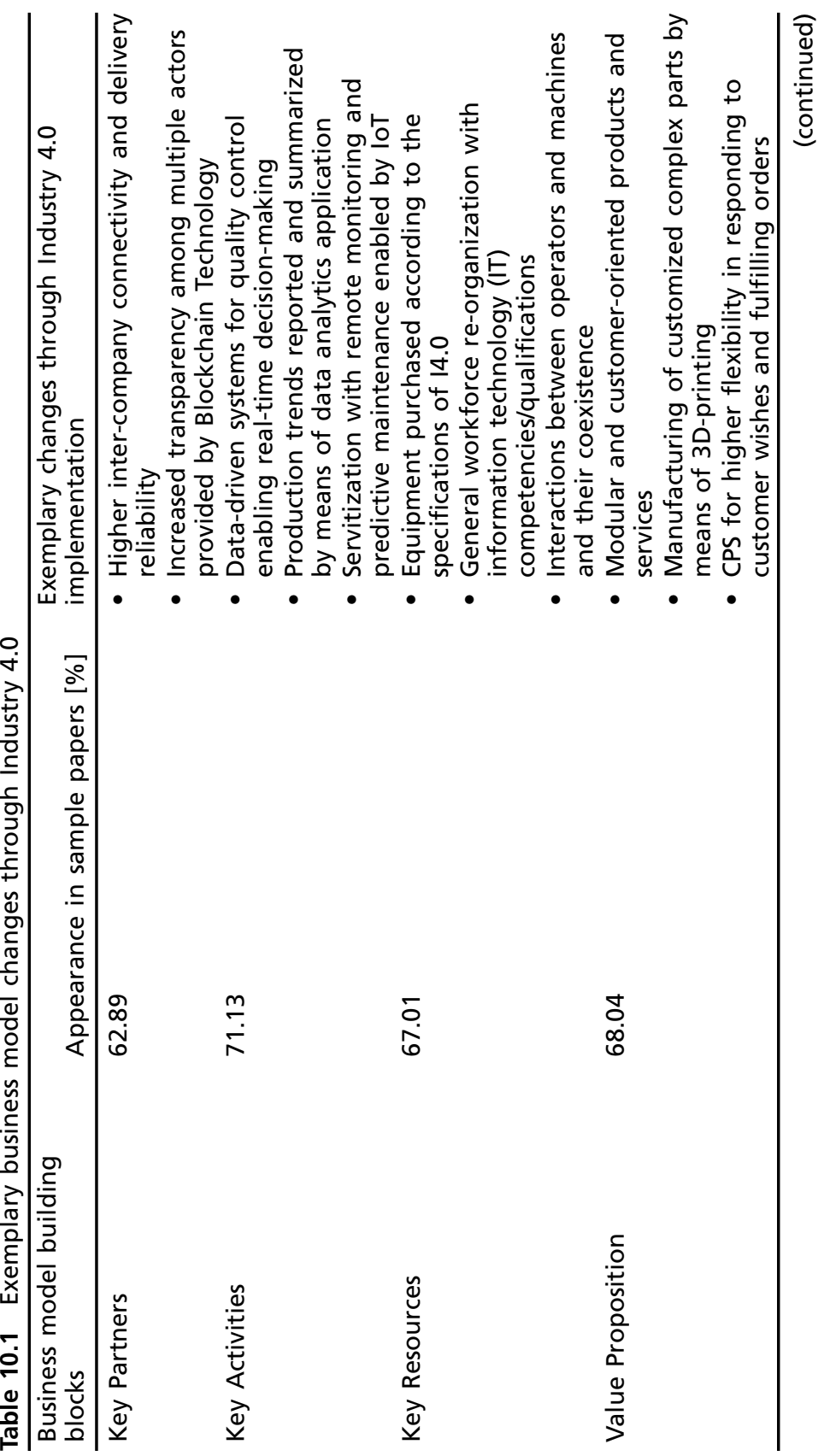




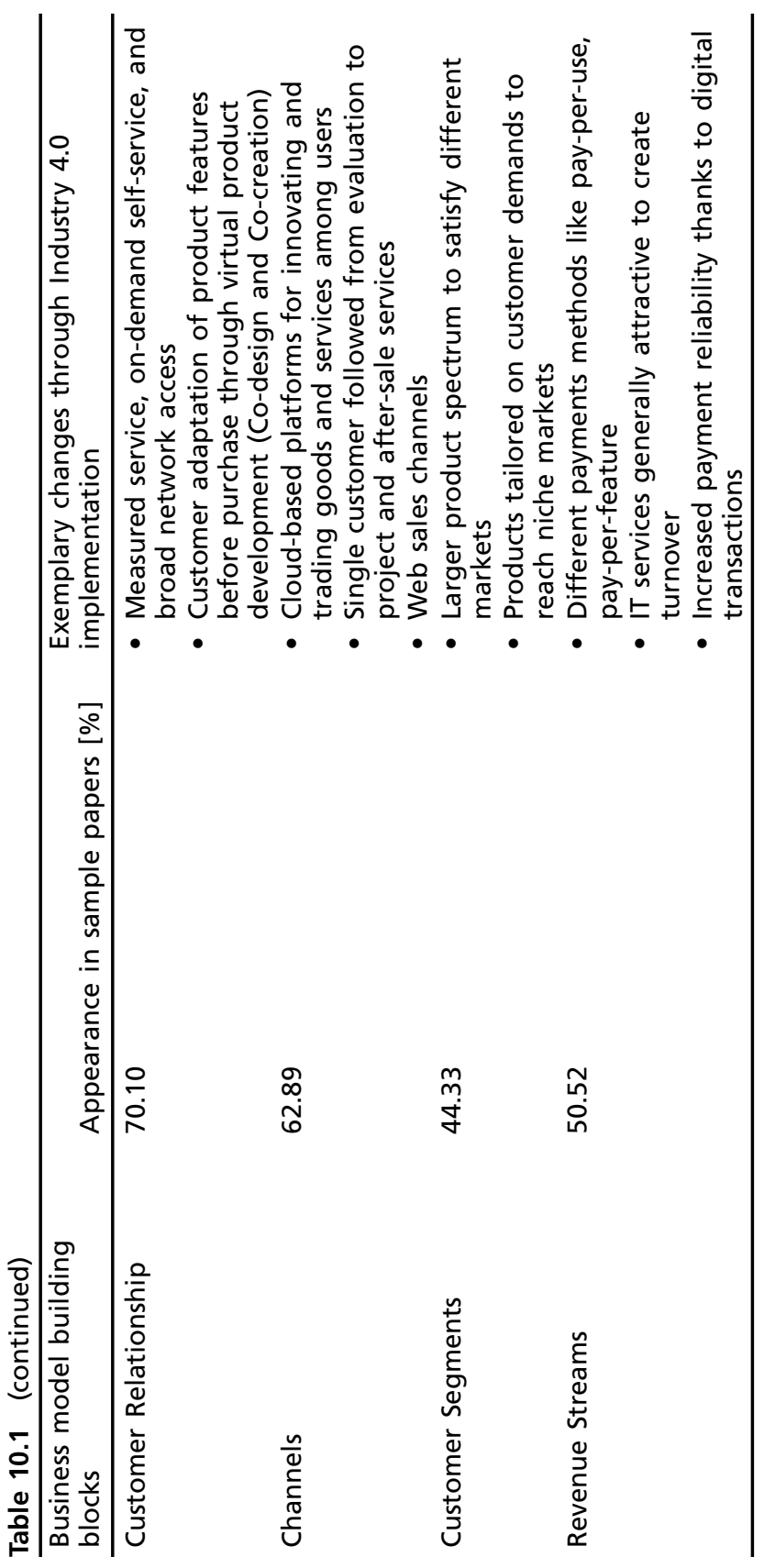




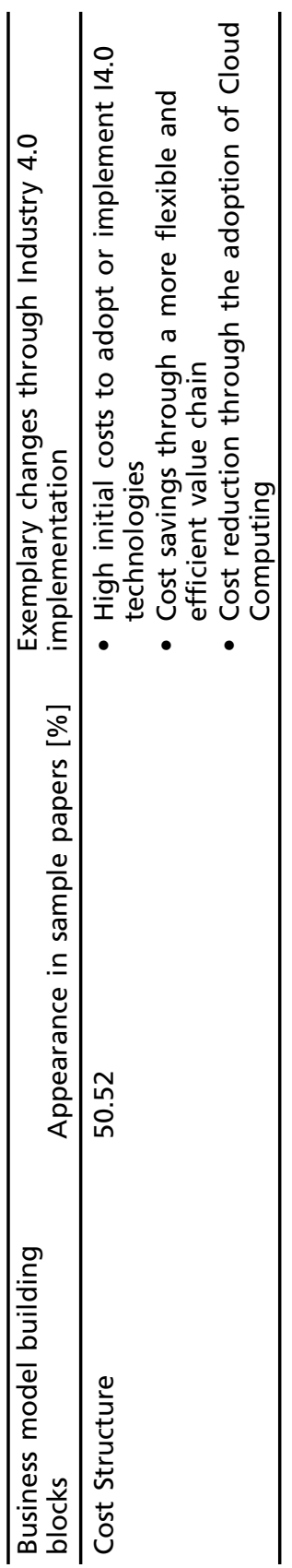


Less than $45 \%$ of the articles talk about the importance of I4.0 technologies in order to satisfy different Customer Segments. Furthermore, technological innovations can seldom be used without redesigning the BMs of established companies, requiring them to incorporate new external knowledge into internal activities, which explains why the Key Partners building block results to be often mentioned in literature (over $60 \%$ ). SMEs in particular are encouraged to cooperate with partners that can help them to transform and exploit external knowledge related to I4.0 (Müller et al. 2020). Dynamic capabilities include a firm's ability to integrate, build, and reconfigure external and internal resources to address and shape rapidly changing environments (Brenner 2018). Key Resources are cited by over $65 \%$ of the articles, in which the intellectual resources play a fundamental role. Workers, in fact, possess higher autonomy and levels of participation in decision-making processes, modifying their place in the firm's ecosystem from bare performers to active cooperators.

\subsubsection{Contingency Analysis of Industry 4.0 Technologies and Business Model Building Blocks}

The contingency analysis complements the qualitative analysis as a second analytical step. It discloses connections among the codes and enables the identification of hot topics and gaps in the reviewed literature (Sauer and Seuring 2017).

The analysis focuses on association pattern among the two code sets that are central to this study, i.e., the nine BM blocks and the eleven I4.0 technologies. Both were complemented by an overarching code "Business Model in general" or "Industry 4.0 in general" used if the level of detail of investigation did not justify the more detailed coding into a BM block or I4.0 technology. The contingency analysis investigates the resulting three possible association patterns of (1) I4.0 technology to I4.0 technology, (2) BM block to I4.0 technology, and (3) BM block to BM block. Since the associations do not have a direction, the code sequences do not make a difference. The significant associations are displayed in the following Tables 10.2, 10.3, and 10.4. 
Table 10.2 Results of the contingency analysis of 14.0 technologies

\begin{tabular}{|c|c|c|c|c|c|c|}
\hline & Code 1 & Code 2 & Count & $\begin{array}{l}\text { Expected } \\
\text { count }\end{array}$ & Phi & $\begin{array}{l}\text { Approximate } \\
\text { significance }\end{array}$ \\
\hline \multirow{7}{*}{$\begin{array}{l}\text { Industry } \\
4.0 \\
\text { technology } \\
\text { to } \\
\text { Industry } \\
4.0 \\
\text { technology }\end{array}$} & $\begin{array}{l}\text { Advanced } \\
\text { Robotics }\end{array}$ & $\begin{array}{l}\text { Cloud } \\
\text { Computing }\end{array}$ & 14 & 6.2 & 0.453 & 0.000 \\
\hline & $\begin{array}{l}\text { Additive } \\
\text { Manufacturing }\end{array}$ & $\begin{array}{l}\text { Cloud } \\
\text { Computing }\end{array}$ & 14 & 7.8 & 0.325 & 0.001 \\
\hline & $\begin{array}{l}\text { Big Data } \\
\text { Analytics }\end{array}$ & $\begin{array}{l}\text { Machine } \\
\text { Learning } \\
\text { and Al }\end{array}$ & 22 & 14.4 & 0.373 & 0.000 \\
\hline & $\begin{array}{l}\text { Big Data } \\
\text { Analytics }\end{array}$ & $\begin{array}{l}\text { Cloud } \\
\text { Computing }\end{array}$ & 32 & 23.9 & 0.345 & 0.001 \\
\hline & $\begin{array}{l}\text { Big Data } \\
\text { Analytics }\end{array}$ & $\begin{array}{l}\text { Visualization } \\
\text { Technologies }\end{array}$ & 17 & 10.8 & 0.337 & 0.001 \\
\hline & $\begin{array}{l}\text { Cloud } \\
\text { Computing }\end{array}$ & $\begin{array}{l}\text { Visualization } \\
\text { Technologies }\end{array}$ & 15 & 7.4 & 0.408 & 0.000 \\
\hline & $\begin{array}{l}\text { Cloud } \\
\text { Computing }\end{array}$ & $\begin{array}{l}\text { Internet of } \\
\text { Things }\end{array}$ & 39 & 33.4 & 0.316 & 0.002 \\
\hline
\end{tabular}

Within the I4.0 technologies, Cloud Computing is found to be contingent to five other technologies. Being positively/negatively contingent means that the two related codes have been/have not been coded together in a significant number of papers, meaning that the appearance of both codes is statistically significantly concentrated/spread across shared/divided parts of the total sample of papers. This is evaluated in a Chi-square test assuming a normal distribution of the two codes across the total sample of papers. This finding underlines the enabling character of Cloud Computing for Advanced Robotics, Additive Manufacturing, Internet of Things, and Visualization Technologies. The final contingency is found with Big Data Analytics, that also exhibits the second highest number of associations. In effect, it can be contended that these two technologies are the core enablers of I4.0 implementation.

Turning back to the central role of Cloud Computing and Big Data Analytics, this becomes also evident in Fig. 10.2, that visualizes the results of the contingency analysis for the I4.0 technologies.

Moreover, the grouping of the technologies by Culot et al. (2020) has been added by means of gray rectangles. This underlines the centrality of the network technologies and adds to the characterization of I4.0 technologies and their interrelations. In effect, all four technology groups by Culot et al. (2020) are represented with at least one technology. Still, the fact that the contingency analysis has not yielded significant results 


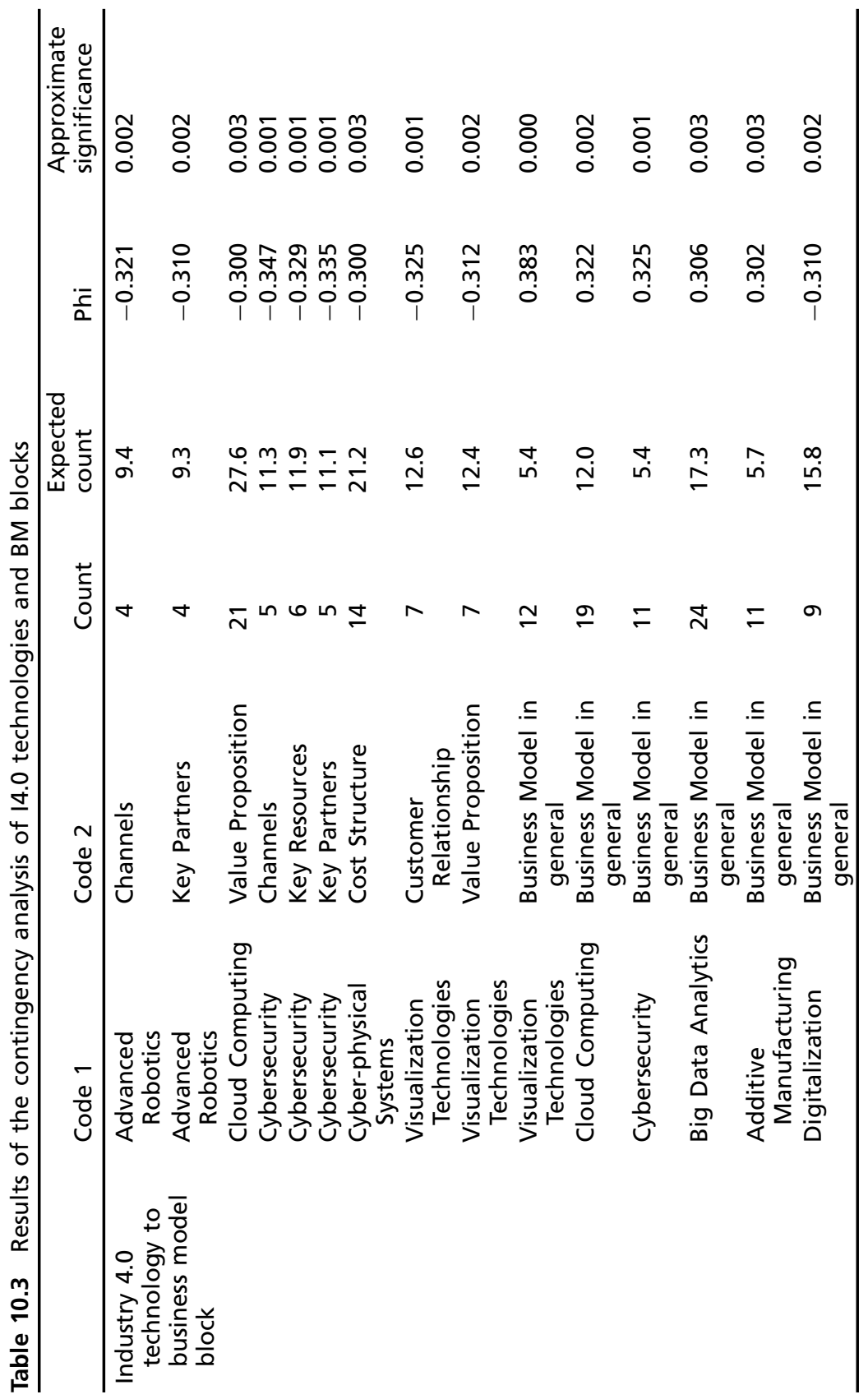




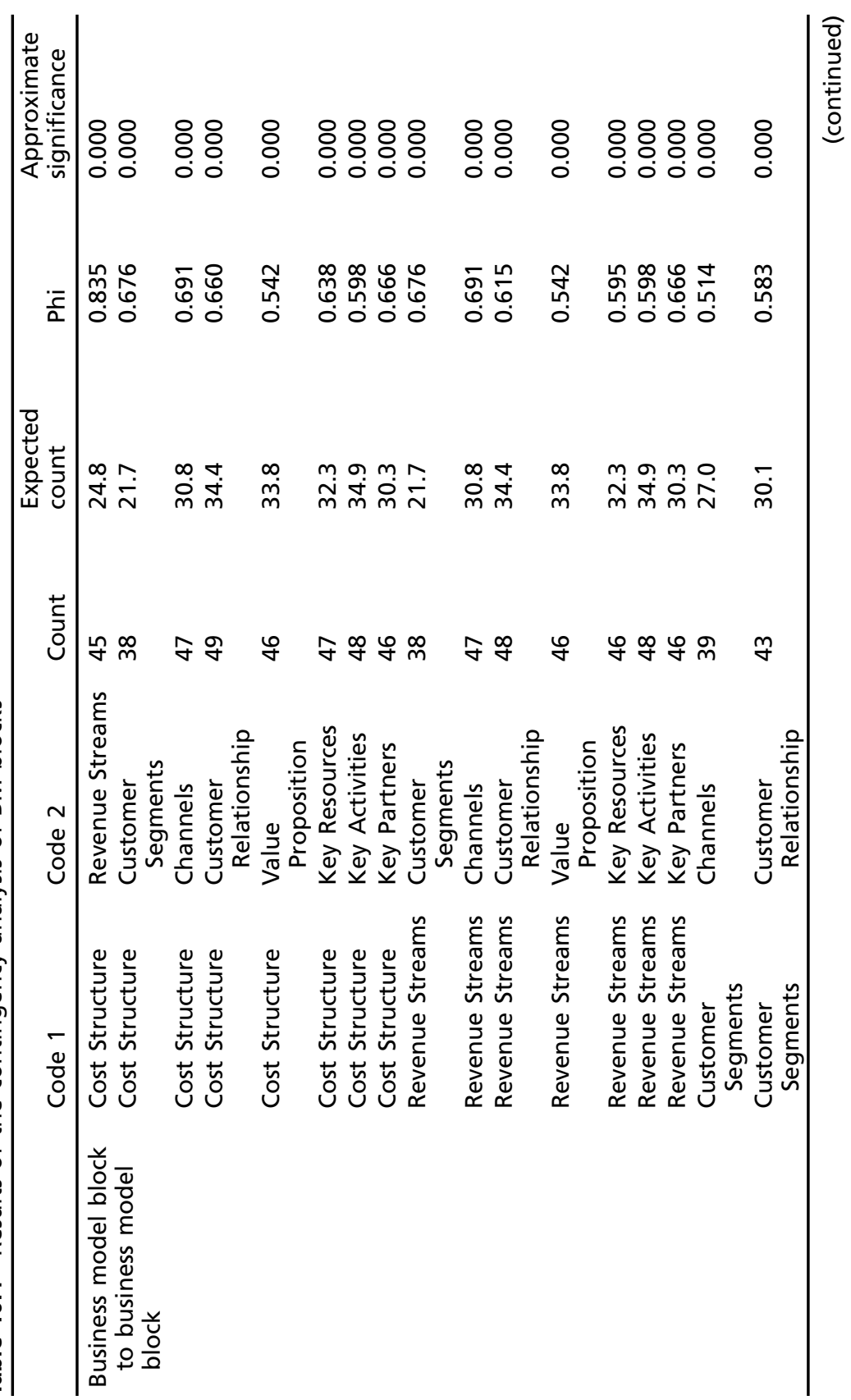




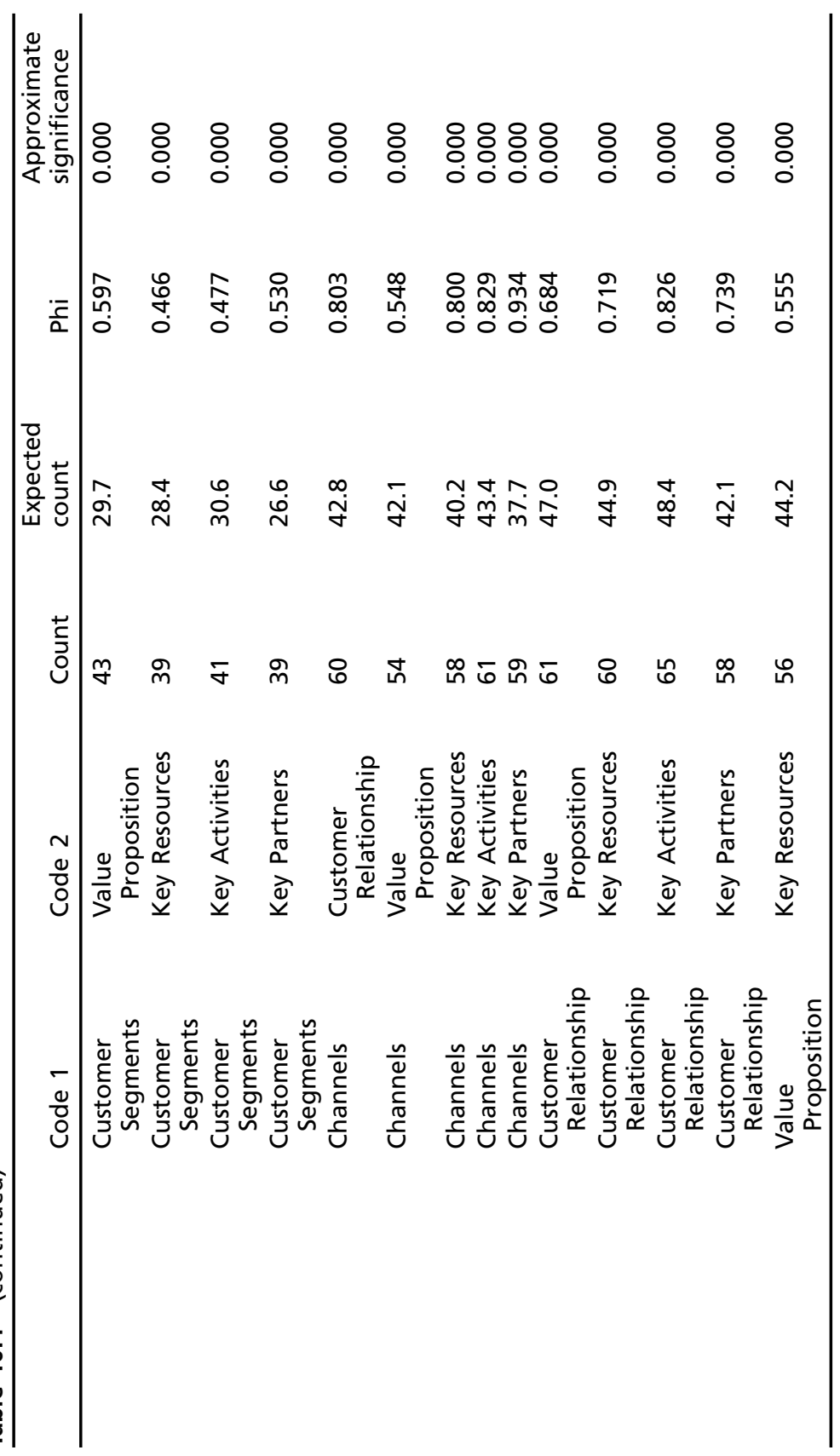




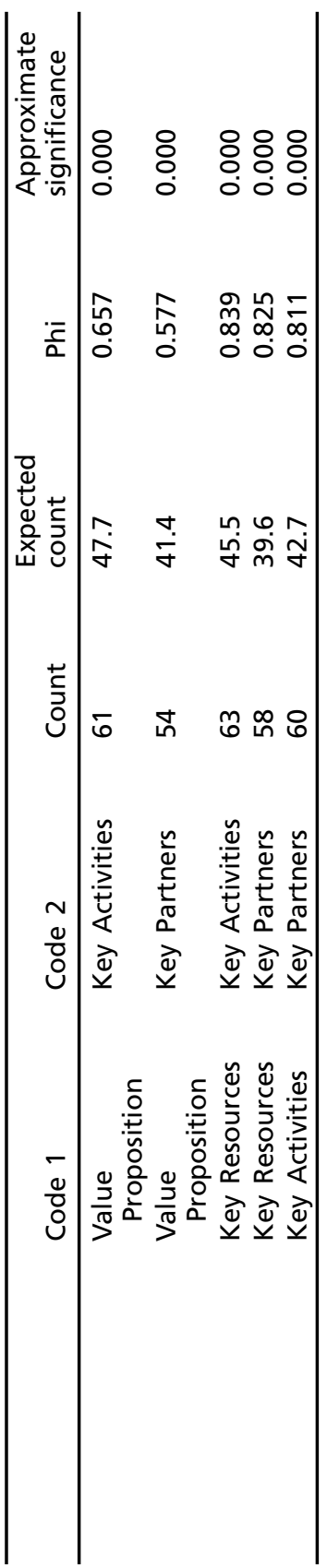




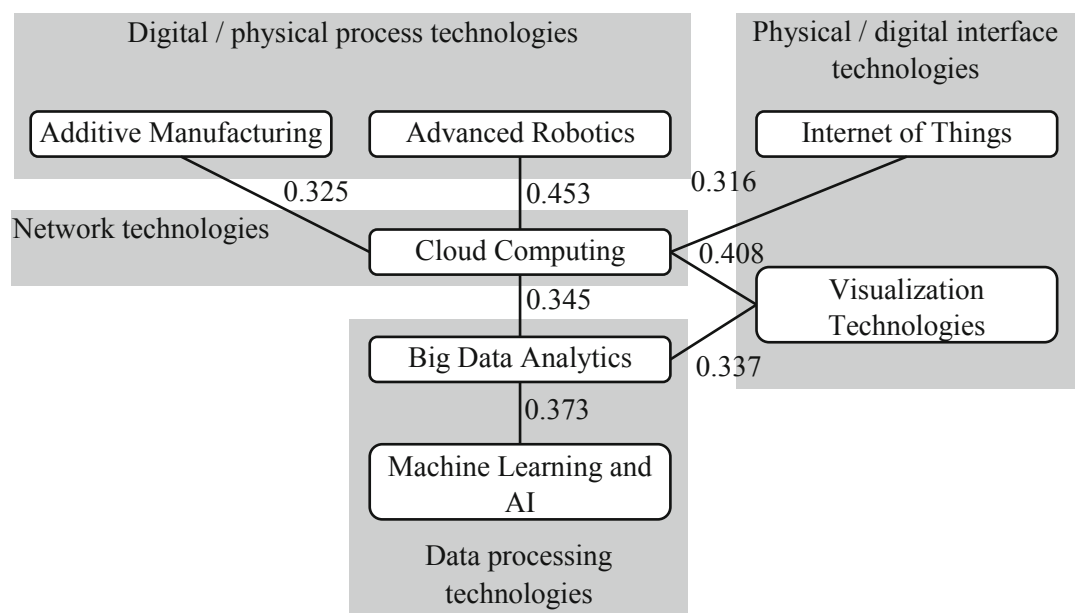

Fig. 10.2 Visualization of the results of the contingency analysis of 14.0 technologies including phi values

for the remaining code combinations underlines that there is no concentration of these combinations throughout the sample. The contingency reveals only outliers in code combinations that are nevertheless displaying the hotspots and gaps in literature. The former is revealed by concentrations of code combinations that signal a relatively intensive investigation of the coded concepts together. Contrastingly, the gaps are revealed if the appearance of the codes is split into separate sub-samples, i.e., the individual concepts are investigated separately, which is indicated by a negative phi value.

The mentioned identification of hotspots and gaps proposed by Sauer and Seuring (2017) can best be seen for this study in the following Table 10.3. Quite distinctively and surprisingly all significant associations among I4.0 technologies and BM blocks exhibit a negative phi value. Contrastingly, there are five significant associations of I4.0 technologies and the overarching code "Business Model in general." This double-sided finding is a strong signal for a lack of detail in the analysis of the intersection of I4.0 technologies and BM blocks or elements. It shows that if the literature is making references to the I4.0 technologies, the respective papers fall short in addressing individual BM blocks but reference 
a general impact on BMs. However, Table 10.3 also underlines that this is not the case for all the eleven technologies, but only five technologies exhibit the negative associations that indicate an under-researched intersection between these constructs.

Among those five technologies, Cybersecurity is certainly the most interesting one. It has been found only half as often as statistically expected in conjunction with the BM blocks of Channels, Key Partners, and Key Resources. This is surprising since Cybersecurity has been found to be key to the intra- and inter-organizational application of I4.0 (Kagermann et al. 2013; Culot et al. 2020). It should thus take a more central role in future research that could investigate the role of Cybersecurity to enable the implementation of I4.0 and the modification of a firm's BM.

As displayed in Table 10.4 all nine BM blocks are found to be contingent to each other, meaning that relative to the pool of all 22 codes the associations between the BM block codes appear statistically significantly more often than expected against a normal distribution. At the same time, the results are by far more mixed for the 14.0 technologies. This indicates the relative maturity of the BM domain and the high applicability of the BM canvas framework for the literature at the researched intersection. Moreover, the BM literature underlines that a change in one BM block likely impacts the other blocks as well (Spieth and Schneider 2016).

As a maximal used association, 65 papers investigate both Customer Relationships and Key Activities. This is however unsurprising given that one of the core purposes of a firm is the satisfaction of customer needs and thus naturally linking all activities to the relation to the customer. This association is, however, not the strongest with a phi value of 0.826 . The strongest one is between Channels and Key Partners (phi = 0.934), which is again due to the closely related content of the codes. Turning to the weakest links, these are found among Customer Segments and Key Resources (phi $=0.466$ ) and Customer Segments and Key Activities (phi $=0.477$ ). Still, all phi values of the associations among the BM blocks are higher than the ones among the I4.0 technologies in Table 10.2 and the intersection of both displayed in Table 10.3 underlining the interconnectedness of the BM blocks in the reviewed literature. 
As outlined before, literature reviews and literature-based contingency analysis are limited in their representation of practice. To address this shortcoming, the subsequent section presents the results of the analysis of the company data on the interrelation of I4.0 technologies and BMs.

\subsubsection{Secondary Data Analysis}

To provide an empirical contribution to the research question, the 30 analyzed SMEs have been categorized in a matrix of I4.0 technologies and BM blocks in Table 10.5. These results are presented in the following and based on them propositions have been built to underline how I4.0 technologies can help to modify an SMEs BM.

Throughout the sample of 30 SMEs, IoT has been found six times, making it one of the most widespread I4.0 technologies in the sample. The companies relate it to a total of four BM blocks. Firstly, IoT is found to enable communication across a wide array of systems and services and allows to develop vertical solutions for connected products, people, and value chains [1]. This makes it a valuable enabler of Key Activities in basically any industry. Moreover, the implementation of IoT is considered useful in the mechanical industry [16] for a better production re-organization to move the entire information flow into the digital sphere. Secondly, IoT also has an impact on the Value Proposition improving business efficiency and performance and supporting innovation in the case of a consulting services company by means of the collection and real-time data analytics through sensors [6]. Thirdly, Customer Relationships are found to benefit from end-to-end solutions including the installation of IoT devices through the enforcement of connectivity, up to data acquisition and analysis [5]. In the mechanical manufacturing industry, IoT has been implemented to establish real-time monitoring solutions thanks to the interconnection between systems, in order to facilitate customers personal assistance [18]. Finally, IoT has been found to enhance production with a series of sensors that enable automatic progressive tracking system from raw materials to the finished product [24]. 


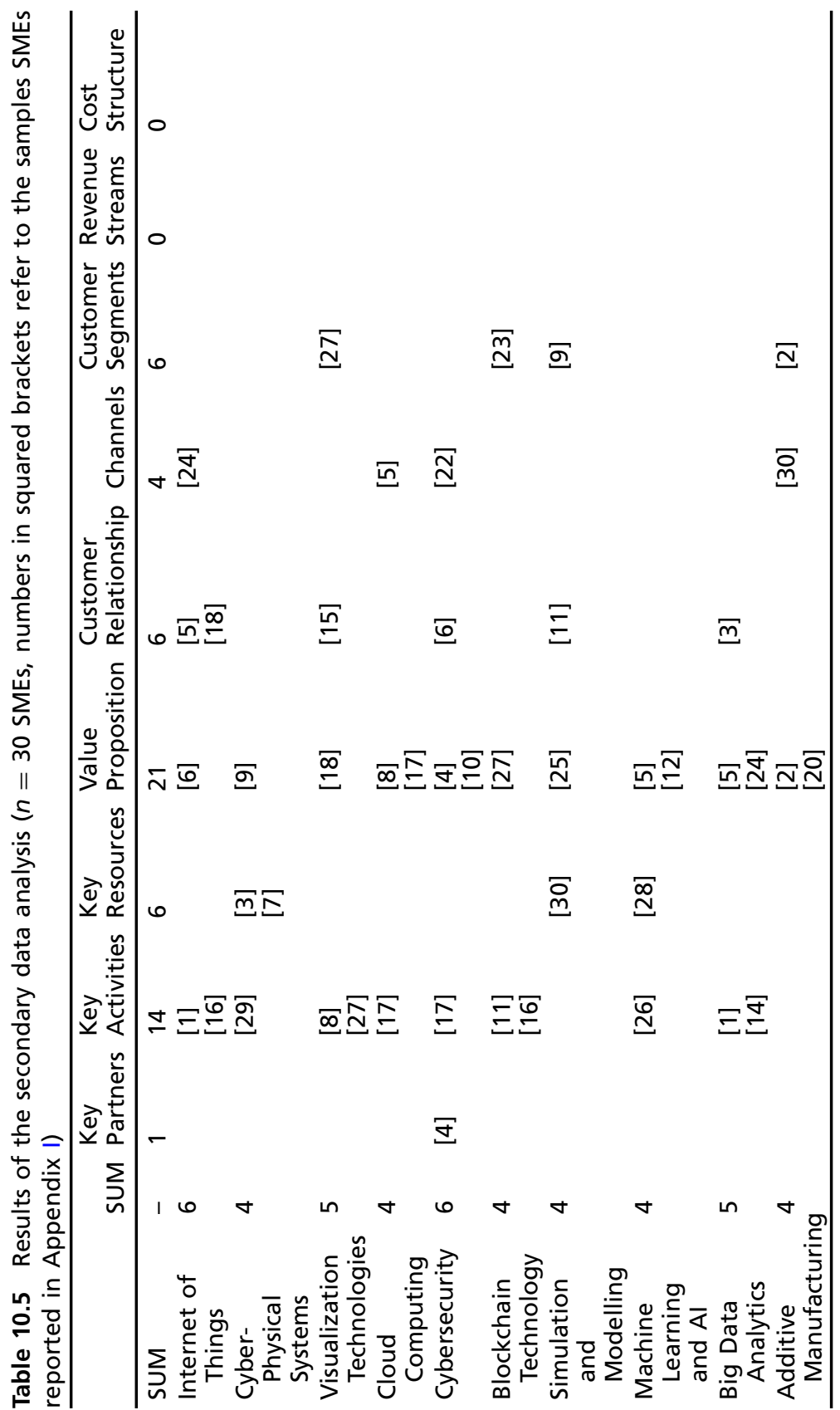


P. C. Sauer et al.

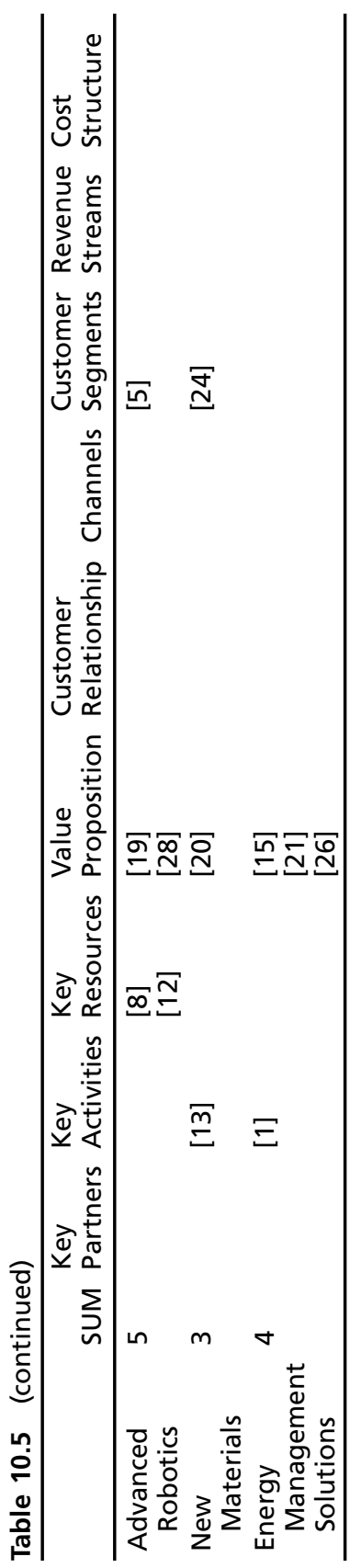


In effect, the SME examples underline the potential modifications of BM blocks of SMEs by implementing IoT. This can be summarized in Proposition 1: Internet of Things can improve Key Activities and Value Proposition, facilitate Customer Relationship, and simplify Channels.

The application of CPS in an industrial environment has been found to facilitate physical processes by complementing them with digital ones. The four examples found relate to Key Resources and Value Propositions. The former is underlined by the claim that by creating a direct connection between the physical world of machines and products and the virtual world of services and applications, people, processes, and objects can constantly communicate with each other in real time [3]. Similarly, CPS solutions can be used to allow communication and interconnection between different Key Resources (human, physical, and intellectual) in a flexible way [7]. The latter is mainly connected to improved performance. For example, collaborative (man-machine) applications enable the control of robots during complex assembly phases [9]. In a similar way, human-machine collaboration has been found to be essential for the Key Activities of smart testing and optimization of logistics and manufacturing that are again benefitting from the accelerated communication and data exchange as well as the substitution of for example repetitive or dangerous manual labor [29].

These findings from the SME examples can be summarized in Proposition 2: Cyber-Physical Systems can support Key Resources, Key Activities, and Value Proposition.

Visualization Technologies like AR facilitate to have the right data at the right time for better efficacy and efficiency [8] (see also Dallasega et al. 2020). In the case of another firm [27], augmented reality visors are programmed to support operators during machine interventions and provide real-time remote support to customers. Moreover, AR allows to be quick, efficient, and performant while interacting with customers, thus enhancing the firm's Value Proposition [18]. As an interesting example, a packaging company [15] guarantees personal guidance through a remote video assistance service. It works through an app and results extremely useful when real-time instructions on maintenance operations have to be shared with customers, supporting a sustained Customer Relationship. For a firm whose products are totally customized 
[27], sophisticated vision systems respond to the different customers' needs related to quality control, managing dimensional control, defect detection, chromatic variance, and surface finishing defects allowing to satisfy any Customer Segment.

These findings from the SME examples can be summarized in Proposition 3: Visualization Technologies can boost Key Activities and Value Proposition, strengthen Customer Relationship, and satisfy different Customers Segments.

For an integrated systems company [17], Cloud Computing and virtual data storage represents an essential Key Activity to allow information to be accessed remotely anywhere by means of any devices. This activity also improves the Value Proposition offered to customers whose data are collected in the cloud in order to have a unified communication and accessibility [17]. Another example [8] underlines that data storing in Cloud Computing results in major savings since data collection, storage, and analysis, as well as operations and maintenance costs are reduced. Finally, Cloud Computing enables to offer customers a personal assistance in all phases of a project from evaluation to aftersales. It is interesting to see that the edge between Customer Relationship and Channels is often blurred when it comes to consulting services companies, due to the nature of the services involved [5].

These findings from the SME examples can be summarized in Proposition 4: Cloud Computing can improve Key Activities, Value Proposition, and Channels.

To secure Key Partners' information and protect their data, Cybersecurity offers innovative solutions for intrusion detection, identity and access management, and antispyware as key activities [17]. This is complemented by the collaboration with professional partners in the field of data protection to offer customers a privacy impact assessment [4]. Cybersecurity related Value Propositions aim at simplifying, optimizing, and accelerating a firms' managing and operations processes, by ensuring disaster recovery and Cybersecurity [4]. This is found to be a continuous challenge for which offers are available that help customers to update their Cybersecurity system keeping it aligned to the evolution of cyber-risks [10]. 
Similarly, Customer Relationship management can be improved through solutions for backup, disaster recovery, network, and data protection [6]. Finally, customers can be protected and guaranteed a secure connection and communication by means of encryption. In this way, data is protected and intrusion or external interference is avoided [22].

These findings from the SME examples can be summarized in Proposition 5: Cybersecurity can benefit Key Partners, Key Activities, Value Proposition, Customer Relationships, and Channels.

Blockchain Technology allows full product traceability through advanced inventory management systems [11]. This can be seen as a fundamental Key Activity as it also improves internal communication thanks to the evolution of machines' data acquisition [16]. Customers are supported in Big Data management, since complex data are easier to understand for both managers and factory workers thanks to personalized and interactive dashboards [27]. In this way, Blockchain Technology enhances Value Proposition since firms can offer their clients fully customized services supported by the identification and tracking of what is going on through the supply chain. Finally, Blockchains enable that the collected data are processed and integrated to generate valuable information for new intelligent maintenance activities and to preempt production delays affecting the availability of goods to the customers [23], thus satisfying different Customer Segments.

These findings from the SME examples can be summarized in Proposition 6: Blockchain Technology can enhance Key Activities as well as Value Propositions and satisfying different Customer Segments.

Expertise and experience are among the Key Resources of production firms; however, when dealing with quality and excellence, these can be complemented with Simulation and Modelling especially in material testing and failure investigation [30]. The manufacturing industry applies Simulation and Modelling technologies to create better design and manufacturing solutions. Their use limits design mistakes and empirical technical choices and guarantees a high repeatability of the process over time, thus creating the Value Proposition of reducing internal production costs [25]. Furthermore, Simulation and Modelling are useful tools, together with co-creation, to continuously improve 
reliability and performance for customers enhancing the Customer Relationships [11]. Finally, this technology is mainly used by engineering industries, since advanced simulation, modelling, and design processes enable to reach both niche markets, such as the aerospace one, and mass markets, such as the automotive one [9].

These findings from the SME examples can be summarized in Proposition 7: Simulation and Modelling can support the implementation of Key Resources, amelioration of Value Propositions and Customer Relationship, and reaching different Customer Segments.

Artificial Intelligence plays an important role to predict the maintenance of products and facilities or to control anomalies in the industrial environment, i.e., a firm's Key Activities [26]. It is moreover a Key Resource since the cognitive capabilities of the system provide new paradigms of support to the human operator either in purely manual activities or in hybrid human-robot collaborative stations [28]. In an I4.0 view, firms implement machines that are more and more able to learn while they interact with humans. Therefore, they communicate by means of a more natural language which is accessible and usable by anyone [5]. Artificial Intelligence concentrates on mimicking human decision-making processes and carrying out tasks in ever more human ways, helping to optimize the production process as a Key Resource, and driving an enhanced Value Proposition [12].

These findings from the SME examples can be summarized in Proposition 8: Machine Learning and Artificial Intelligence can enhance Key Activities, Key Resources, and Value Proposition.

Big Data can be collected, stored, and analyzed on a platform, thus establishing secure communication between data center sensors [1]. Besides that, real-time data analytics allows to perform several key activities such as predictive maintenance, downtime reduction, analysis performance, and optimization of business processes that are Key Activities in manufacturing [14]. Thanks to data acquisition and analysis, firms can offer more efficient solutions, flexibility, and servitization, as well as constant and continuous improvement of production processes, i.e., the Value Proposition [5, 24]. Finally, Customers Relationships can be enhanced by giving personal assistance throughout the whole 
activity process from data capture and processing, to planning, execution, real-time monitoring, and quality controls [3].

These findings from the SME examples can be summarized in Proposition 9: Big Data Analytics can boost Key Activities, Value Propositions, and Customer Relationships.

Among the Value Propositions, Additive Manufacturing technology can reduce production times and costs, thus optimizing the whole manufacturing process, which is a Key Activity [2]. This is achieved by facilitated creation of complex shapes, while 3D-printing reduces inaccuracies in projects, cuts development costs, decreases human errors, avoids waste of materials, and speeds up product marketing [20]. By evaluating all aspects of a product, from the choice of raw materials to the analysis of the process, it is possible to appreciate how Additive Manufacturing can connect a variety of industrial fields [30]. Finally, a simulation driven engineering company uses additive manufacturing technology to satisfy different Customer Segments' needs for both prototyping and designing of metal components [2].

These findings from the SME examples can be summarized in Proposition 10: Additive Manufacturing can modify Value Proposition, improve Key Activities as well as Channels, and satisfy different Customer Segments.

Robots are seen as Key Resources, since they represent "virtual workers" taking on tedious and repetitive tasks [8]. Advanced robotics has to be smartly integrated in the industrial scenario, in order to let workstations become ergonomic and flexible, avoiding stressful jobs for human workers [12]. The introduction of smart robots enhances operating speed and product quality, thus offering changes Value Propositions based on saving time and money, reducing human errors, decreasing waste and rework, and allowing a higher job rotation flexibility [19, 28]. Finally, collaborative Robots, which can interact actively and recognize human voice command, can be used in different sectors being suitable for plenty of businesses, thus satisfying a variety of Customer Segments [5].

These findings from the SME examples can be summarized in Proposition 11: Advanced Robotics can build Key Resources, change Value Propositions and Customer Segments.

Even if New Materials can hardly be defined as an I4.0 technology in general, "smart materials" possessing smart properties are 
an enabler of I4.0 (Culot et al. 2020). New Materials are used in a variety of Key Activities, for example, to enhance surface finishing or perform non-destructive inspection of parts by using magnetic particles, water washable, and post-emulsifiable liquid penetrants and contact and immersion ultrasonic [13]. Most New Materials are developed from existing materials by means of new combinations of elements. The design and production of new polymeric advanced materials for additive manufacturing results in high performance in terms of thermo-mechanical resistance and advanced functional properties, representing new Value Propositions [20]. Finally, New Materials help to reach new Customer Segments and offer infinite mixing possibilities to satisfy any kind of requests [24].

These findings from the SME examples can be summarized in Proposition 12: New Materials can enrich Key Activities, improve Value Proposition, and reach more Customer Segments.

Monitor energy consumption and finding energy saving solutions have become Key Activities. This may be obtained by platforms able to collect and remotely control data, as well as calculate the amount of energy consumption and losses in several working conditions [1]. The continuous improvement of environment impact by means of energy produced from different renewable sources, re-used wastewater and photovoltaic systems plays an essential role in the Value Proposition of many firms. For instance, to reduce the consumption of energy and water, a photovoltaic plant can be installed or to minimize the consumption of waste, recycling can be implemented $[15,21]$. There are also several technologies that use natural, renewable sources to recharge devices' batteries, thus decreasing the need for maintenance and the negative impact on the environment [26].

These findings from the SME examples can be summarized in Proposition 13: Energy Management Solutions can improve Key Activities and Value Propositions. 


\subsection{Discussion and Conclusion}

This study sets out to answer the research question of how can the implementation of Industry 4.0 technologies drive the modification of the business models of small- and medium-sized enterprises?

The findings reveal the double-sided nature of the intersection of I4.0 technologies and BMs including their building blocks. This encompasses on the one hand the concept of BM that is found in this study to be well established in its conception as well as application. Both literature and practice on BMs investigate multiple blocks in conjunction, acknowledging the impact of one on another. This supports previous literature that found the relative high interconnectedness of BM blocks (Spieth and Schneider 2016; Kotarba 2018), no matter if the BM canvas or other frameworks are used. On the other hand, this interconnectedness is particularly striking in comparison to the results obtained in the evaluation of the I4.0 technologies that exhibit a much higher heterogeneity. In line with previous literature, I4.0 is found to be in a constant flux. This finding has been formulated from the beginning of the concept (Kagermann et al. 2013) until some of the most recent publications on it (Culot et al. 2020). The found heterogeneity moreover supports that there are no fixed rules for I4.0 implementation (Botha 2019) and that the revolutions in production require a reflection in the BM (Porter and Heppelmann 2014). Despite this flux, the study at hand supports Müller and Däschle (2018) that underline the value of technical innovations that are associated to I4.0 innovations for strengthening existing BMs or developing new ones. The propositions developed in Sect. 10.4.2 provide detailed guidance based on practice examples of this interrelation.

A particular interesting finding is the mixed results on the relation of Cybersecurity and the BM blocks. In line with literature, the empirical results find the high relevance of this intersection to reduce the vulnerabilities of a digitalized firm (Culot et al. 2020; Götz and Jankowska 2017; Kotarba 2018). Contrastingly, the literature-based contingencies in Sect. 10.4.2 identify an underrepresentation of investigations of Cybersecurity and Key Partners, Channels, and Key Resources. Additionally, in literature there is an overrepresentation of associations of Cybersecurity to BMs in general. Turning to the details of the SME 
specific empirical findings in Sect. 10.4.2, these identify examples for two of the three combinations. This indicates a need for further investigations and clarifications that gain relevance considering the rapidly rising digitalization of firms and public organization in the course of the Corona crisis (Karabag 2020).

The findings moreover support the notion that I4.0 enabling technologies have the potential to substantially change how organizations and complex systems are managed (Leminen et al. 2018).

Turning from the contributions to the limitations of the study, we contend that any study (in particular literature reviews and secondary data analyses) exhibits limitations and aims at the generation of research direction to enable further work. While the measures to ensure reliability, replicability, and validity have already been elaborated in Sect. 10.3, the extant study still entails three main limitations. Nevertheless, these limitations can guide the way to future research and both are presented in more detail below:

First, the data collection is limited, since it exclusively investigated literature and website contents. Although this represents written communication from relevant practitioner and scientific sources, primary data from interviews for example would be timelier and most likely richer in the description of the relation of the I4.0 technologies and the BM blocks. Based on this, follow-up research could be based on primary data collection such as semi-structured interviews or focus groups. These could be structured into the single I 4.0 technologies and BM blocks to enable richer descriptions of the interrelations. Alternatively, the relatively well-established concepts used in this study could build the basis for quantitative investigations. Starting from less formalized approaches like an analytical hierarchy process, the importance of the individual I4.0 technologies for the modification of the BM blocks could be investigated. Moreover, such follow-up empirical research could provide a validation for the propositions given in Sect. 4.2, whose validity and generalizability are limited by the data source.

Second, the data analysis is limited by the adoption of a single framework for I4.0 and BM each and their deductive application in content analysis. This limits the findings to the concepts captured in the frameworks and hinders the investigation of potentially relevant issues beyond. 
Starting from here, a replication of the study with an enlarged set of frameworks could be worthwhile. This could also serve to investigate the overlaps of the chosen frameworks and establish a more appropriate one for the researched intersection of I4.0 technologies and BMs and their elements.

Third, the extant study is limited by the restricted granularity of the data collection and analysis, since it analyzed the literature and SMEs without a distinction of industries, countries, or continents from which they originated. Therefore, follow-up research could take an industry as well as country focus to investigate the heterogeneity of implemented I4.0 technologies, BMs, and their intersection. Although the frontier between products and services as well as industries and countries are gradually disappearing, it is still relevant to identify frontrunners and best practices, since their investigation and dissemination have high practical relevance in supporting the innovativeness of SMEs that represent the backbone of our economies.

Finally, the contingency analysis found an underrepresentation of publications on Cybersecurity and the BM blocks of Channels, Key Partners, and Key Resources, that however have been found to be relevant and require further investigations.

In effect, the findings of this study can guide practitioners and in particular managers of manufacturing firms and supply chains. The literature review findings provide an orientation of the state of the art in research on the impact of I4.0 technologies on BM blocks. Moreover, the empirical findings provide a map of 30 innovative SMEs that can be seen at the forefront of I4.0 implementation in one of Europe's main economies, i.e., Italy. This map is complemented by the abstraction of it into a set of propositions providing guidance on how I4.0 technologies have modified the BM blocks after successful implemented in manufacturing companies.

Acknowledgements This project has received funding from the European Union's Horizon 2020 research and innovation program under the Marie Skłodowska-Curie grant agreement No 734713. 


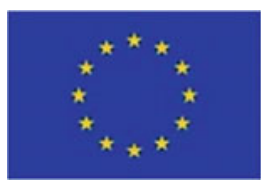

\section{Appendix I: 30 Sample SMEs}

\begin{tabular}{|c|c|}
\hline Firm & Sector \\
\hline $\begin{array}{l}\text { [1] ABO DATA } \\
\text { http://wwww.abodata.com/ }\end{array}$ & $\begin{array}{l}\text { Consulting and technology } \\
\text { projects to support customers' } \\
\text { digital transformation through } \\
\text { the implementation of IT } \\
\text { solutions }\end{array}$ \\
\hline $\begin{array}{l}\text { [2] ADDITIVE ITALIA } \\
\text { http://www.add-it.tech/ }\end{array}$ & $\begin{array}{l}\text { Additive manufacturing firm } \\
\text { specialized in simulation driven } \\
\text { engineering and design for } \\
\text { metal addictive manufacturing }\end{array}$ \\
\hline $\begin{array}{l}\text { [3] AEC SOLUZIONI } \\
\text { http://www.aecsoluzioni.it/wp/ }\end{array}$ & $\begin{array}{l}\text { Engineering and development } \\
\text { of software solutions to help } \\
\text { businesses to manage and to } \\
\text { improve their manufacturing } \\
\text { processes and efficiency with a } \\
\text { view to } 14.0 \text { technologies }\end{array}$ \\
\hline $\begin{array}{l}\text { [4] AGOMIR } \\
\text { https://www.agomir.com/ }\end{array}$ & $\begin{array}{l}\text { Software solutions: from } \\
\text { software application to } \\
\text { infrastructure projects, from } \\
\text { technical assistance to training, } \\
\text { in order to better managing } \\
\text { processes and a firm's } \\
\text { organization }\end{array}$ \\
\hline $\begin{array}{l}\text { [5] ALASCOM SERVICES } \\
\text { https://www.alascom.it/ }\end{array}$ & $\begin{array}{l}\text { System integrator and supplier } \\
\text { of technical consulting ICT } \\
\text { services, with a specific focus } \\
\text { on telecommunications } \\
\text { networking and IP } \\
\text { technologies }\end{array}$ \\
\hline $\begin{array}{l}\text { [6] BEANTECH } \\
\text { https://www.beantech.it/ }\end{array}$ & $\begin{array}{l}\text { Consulting services company, } \\
\text { supporting clients in their } \\
\text { digital transformation facing } \\
\text { the challenges of } 14.0\end{array}$ \\
\hline
\end{tabular}


(continued)

\begin{tabular}{|c|c|}
\hline Firm & Sector \\
\hline $\begin{array}{l}\text { [7] BEATREEX } \\
\text { https://www.beatreex.it/ }\end{array}$ & $\begin{array}{l}\text { Software systems and } \\
\text { cyber-physical software for the } \\
\text { digital transformation to } \\
\text { satisfy a firm's ever-changing } \\
\text { production needs }\end{array}$ \\
\hline $\begin{array}{l}\text { [8] E.MAGINE } \\
\text { https://emagine.ai/ }\end{array}$ & $\begin{array}{l}\text { Consulting and management } \\
\text { services able to offer tailored } \\
\text { solutions, to create and realize } \\
\text { innovative projects, supporting } \\
\text { customers in strategic choices }\end{array}$ \\
\hline $\begin{array}{l}\text { [9] EGICON } \\
\text { http://www.egicon.com/ }\end{array}$ & $\begin{array}{l}\text { Engineering firm for advanced } \\
\text { electronic systems, committed } \\
\text { to offer their customers the } \\
\text { best technology for } \\
\text { development and production }\end{array}$ \\
\hline $\begin{array}{l}\text { [10] FASTERNET SOLUZIONI DI } \\
\text { NETWORKING } \\
\text { https://wwww.fasternet.it/ }\end{array}$ & $\begin{array}{l}\text { Information and communication } \\
\text { technology engineering bound } \\
\text { to technological improvement } \\
\text { and innovation through } \\
\text { customized networking } \\
\text { services }\end{array}$ \\
\hline $\begin{array}{l}\text { [11] FLUID-O-TECH } \\
\text { https://www.fluidotech.it/ }\end{array}$ & $\begin{array}{l}\text { Engineering and manufacturing } \\
\text { firm for a variety of } \\
\text { demanding applications, } \\
\text { ranging from medical to } \\
\text { automotive, industrial, and } \\
\text { food service }\end{array}$ \\
\hline $\begin{array}{l}\text { [12] FRE TOR } \\
\text { https://www.fretor.com/ }\end{array}$ & $\begin{array}{l}\text { Mechanical firm in automation } \\
\text { and industrial robotics suitable } \\
\text { for different sectors, from } \\
\text { optical to medical, automotive, } \\
\text { mechanical, and aerospace } \\
\text { industry }\end{array}$ \\
\hline $\begin{array}{l}\text { [13] FUCINE UMBRE TERNI } \\
\text { http://www.fucineumbre.com/ }\end{array}$ & $\begin{array}{l}\text { Mechanical solutions for the } \\
\text { production of highly stressed } \\
\text { structural components for the } \\
\text { aerospace industry, forged and } \\
\text { finished parts ready for being } \\
\text { used in the assembly lines }\end{array}$ \\
\hline $\begin{array}{l}\text { [14] G2 DI GHIOLDI } \\
\text { https://g2team.it/ }\end{array}$ & $\begin{array}{l}\text { Automation firm active in } \\
\text { different fields dealing with } \\
\text { machine manufacturers in a } \\
\text { variety of sectors from } \\
\text { automotive to food and } \\
\text { chemical industries }\end{array}$ \\
\hline
\end{tabular}


(continued)

Firm
[15] GALDI
https://www.galdi.it/
[16] INTERMEK
https://Www.intermek.com/it/
[17] LAN SERVICE
https://wWw.lanservicegroup.it/ITA

[18] MANDELLI SISTEMI

https://www.mandelli.com/it/

[19] MASMEC

https://www.masmec.com/

[20] MAT3D

https://mat3d.it/

[21] MECCANICA SBARZAGLIA

https://www.meccanicasbarzaglia.com/

[22] MECT

https://www.mect.it/

Sector

Packaging firm designing and producing filling solutions in cartons for milk, dairy products, fruit juice, dry food, with the utmost care in food safety and process repeatability over time

Precision mechanical firm present in various industrial sectors, among which textiles, electrical appliances, industrial vehicles, and meteorological equipment

Integrated systems and consulting services company, safely operating on infrastructure and data center of customers directly at their headquarters

Mechanical manufacturing firm specialized, among others, in the aeronautic, oil, and manufacturing sectors

Industrial automation firm specialized in precision technology, robotics and mechatronics, applied to the automotive and biomedical sectors

Additive Manufacturing firm designing and manufacturing new advanced materials for 3D printing in different industrial sectors from prototypes to mold and tools

Precision Mechanical firm specialized in the processing of composite materials and additive manufacturing

Mechatronic manufacturing solutions devoted to production of mechatronic measurement and control systems, offering customized solutions, hardware, firmware, and software 
(continued)

\begin{tabular}{|c|c|}
\hline Firm & Sector \\
\hline $\begin{array}{l}\text { [23] ORCHESTRA } \\
\text { https://www.retuner.eu/ }\end{array}$ & $\begin{array}{l}\text { Integrated smart systems } \\
\text { providing } 14.0 \text { technologies } \\
\text { and solutions to } \\
\text { manufacturing SMEs interested } \\
\text { in real-time monitoring and } \\
\text { control of their own } \\
\text { production assets }\end{array}$ \\
\hline $\begin{array}{l}\text { [24] PERSONAL FACTORY } \\
\text { https://www.personalfactory.eu/ }\end{array}$ & $\begin{array}{l}\text { Powder mixture industry for the } \\
\text { building sector, managing } \\
\text { end-to-end processes and } \\
\text { offering perfectly customized } \\
\text { solutions }\end{array}$ \\
\hline $\begin{array}{l}\text { [25] PROGIND } \\
\text { http://www.progind.it/ }\end{array}$ & $\begin{array}{l}\text { Manufacturing firm specialized } \\
\text { in molds for plastic material } \\
\text { and sheet metal, guarantee } \\
\text { high quality solutions and } \\
\text { products, carefully designed to } \\
\text { respond to customers' needs }\end{array}$ \\
\hline $\begin{array}{l}\text { [26] QWYDDY TECHNOLOGIES OÜ } \\
\text { https://www.qwyddy-tech.com/it/home-en/ }\end{array}$ & $\begin{array}{l}\text { Consulting services company } \\
\text { associating experience and } \\
\text { tradition with upcoming } \\
\text { technologies, supporting } \\
\text { clients in a customized } \\
\text { digitalization process }\end{array}$ \\
\hline $\begin{array}{l}\text { [27] SMART FACTORY } \\
\text { https://www.smartfactory.it/ }\end{array}$ & $\begin{array}{l}\text { Mechatronics firm possessing a } \\
\text { solid mix of competences in } \\
\text { mechanics, electronics, } \\
\text { informatics, and mechatronics, } \\
\text { helping manufacturers to get } \\
\text { closer to } 14.0 \text { technologies }\end{array}$ \\
\hline $\begin{array}{l}\text { [28] SMART ROBOTS } \\
\text { http://smartrobots.it/ }\end{array}$ & $\begin{array}{l}\text { Advanced robotics firm focusing } \\
\text { on the development and } \\
\text { commercialization of } \\
\text { technologies to support } \\
\text { human operators in the } \\
\text { factory }\end{array}$ \\
\hline $\begin{array}{l}\text { [29] STAUFEN.ITALIA } \\
\text { https://www.staufen.it/it/ }\end{array}$ & $\begin{array}{l}\text { Lean management consulting } \\
\text { services company working with } \\
\text { their clients to establish a } \\
\text { sustainable culture of change } \\
\text { inside the business }\end{array}$ \\
\hline
\end{tabular}


(continued)

\begin{tabular}{ll}
\hline Firm & Sector \\
\hline [30] TEC EUROLAB & Materials and products testing \\
https://www.tec-eurolab.com/eu-en/def & services providing technical \\
ault.aspx & $\begin{array}{l}\text { support for aerospace and } \\
\text { defense, automotive and } \\
\end{array}$ \\
& $\begin{array}{l}\text { racing, among many other } \\
\text { industries }\end{array}$ \\
\hline
\end{tabular}

\section{References}

Ahram, T., A. Sargolazei, S. Sargolazei, J. Daniels, and B. Amaba. 2017. Blockchain technology innovations. In 2017 Technology \& Engineering Management Conference (TEMSCON), 137-141. https://doi.org/10.1109/ TEMSCON.2017.7998367.

Alcácer, V., and V. Cruz-Machado. 2019. Scanning the industry 4.0: A literature review on technologies for manufacturing systems. Engineering Science and Technology, an International Journal 22 (3): 899-919. https://doi.org/ 10.1016/j.jestch.2019.01.006.

Ancarani, A., C. Di Mauro, L. Fratocchi, G. Orzes, and M. Sartor. 2015. Prior to reshoring: A duration analysis of foreign manufacturing ventures. International Journal of Production Economics 169: 141-155. https://doi.org/ 10.1016/j.ijpe.2015.07.031.

Armbrust, M., A. Fox, R. Griffith, A.D. Joseph, R. Katz, A. Konwinski, G. Lee, D. Patterson, A. Rabkin, I. Stoica, and M. Zaharia. 2010. A view of cloud computing. Communications of the ACM 53 (4): 50-58. http://doi. acm.org/10.1145/1721654.1721672.

Botha, A.P. 2019. Innovating for market adoption in the fourth industrial revolution. South African Journal of Industrial Engineering 30 (3): 187-198. https://doi.org/10.7166/30-3-2238.

Brenner, B. 2018. Transformative Sustainable business models in the light of the digital imperative-A global business economics perspective. Sustainability 10 (12): 4428. https://doi.org/10.3390/su10124428.

Carbone, V., A. Rouquet, and C. Roussat. 2017. The rise of crowd logistics: A new way to co-create logistics value. Journal of Business Logistics 38 (4): 238-252. https://doi.org/10.1111/jbl.12164. 
Culot, G., G. Nassimbeni, G. Orzes, and M. Sartor. 2020. Behind the definition of industry 4.0: Analysis and open questions. International Journal of Production Economics. https://doi.org/10.1016/j.ijpe.2020.107617.

Dallasega, P., A. Revolti, P.C. Sauer, F. Schulze, and E. Rauch. 2020. BIM, augmented and virtual reality empowering lean construction management: A project simulation game. Procedia Manufacturing 45: 49-54. https://doi. org/10.1016/j.promfg.2020.04.059.

European Commission. 2020. What is an SME? https://ec.europa.eu/gro wth/smes/business-friendly-environment/sme-definition_en. Accessed on 27 January 2020.

Fink, A. 2019. Conducting research literature reviews: From the Internet to paper, 5th ed. Los Angeles: Sage.

Ghanbari, A., A. Laya, J. Alonso-Zarate, and J. Markendahl. 2017. Business development in the Internet of Things: A matter of vertical cooperation. IEEE Communications Magazine 55 (2): 135-141. https://doi.org/10.1109/ MCOM.2017.1600596CM.

Gold, S., S. Seuring, and P. Beske. 2010. Sustainable supply chain management and inter-organizational resources: a literature review. Corporate Social Responsibility and Environmental Management 17 (4): 230-245. https://doi. org/10.1002/csr.207.

Götz, M., and B. Jankowska. 2017. Clusters and Industry 4.0-do they fit together? European Planning Studies 25 (9): 1633-1653. https://doi.org/10. 1080/09654313.2017.1327037.

Hahn, R., S. Spieth, and I. Ince. 2018. Business model design in sustainable entrepreneurship: Illuminating the commercial logic of hybrid businesses. Journal of Cleaner Production 176: 439-451. https://doi.org/10.1016/j.jcl epro.2017.12.167.

Hermann M., T. Pentek, and B. Otto. 2016. Design principles for Industrie 4.0 scenarios. In 49th Hawaii International Conference on System Sciences (HICSS), 3928-3937. https://doi.org/10.1109/HICSS.2016.488.

Hiete, M., P.C. Sauer, S. Drempetic, and R. Tröster. 2019. The role of voluntary sustainability standards in governing the supply of mineral raw materials. GAIA - Ecological Perspectives for Science and Society 28 (S1): 218-225. https://doi.org/10.14512/gaia.28.S1.8.

Ingaldi, M., and R. Ulewicz. 2020. Problems with the Implementation of Industry 4.0 in Enterprises from the SME Sector. Sustainability 12 (1): 217. https://doi.org/10.3390/su12010217. 
Jacob, K., A.-L. Guske, I. Antoni-Komar, S. Funcke, T. Gruchmann, J. Kny, et al. 2019. Governance for the sustainable economy. Institutional innovation from the bottom up? GAIA - Ecological Perspectives for Science and Society 28 (S1): 204-209. https://doi.org/10.14512/gaia.28.S1.6.

Kagermann, H., W. Wahlster, and J. Helbig. 2013. Recommendations for implementing the strategic initiative Industrie 4.0. Final Report of the Industrie 4.0 Working Group, Forschungsunion.

Kamble, S.S., A. Gunasekaran, and S.A. Gawankar. 2018. Sustainable Industry 4.0 framework: A systematic literature review identifying the current trends and future perspectives. Process Safety and Environmental Protection 117: 408-425. https://doi.org/10.1016/j.psep.2018.05.009.

Karabag, S.F. 2020. An unprecedented global crisis! The global, regional, national, political, economic and commercial impact of the coronavirus pandemic. Journal of Applied Economics and Business Research 10 (1): 1-6.

Klein S., S. Schneider, and P. Spieth. 2020. How to stay on the road? A business model perspective on mission drift insocial purpose organizations. Journal of Business Research. https://doi.org/10.1016/j.jbusres.2020.01.053.

Kotarba, M. 2018. Digital transformation of business models. Foundations of Management 10 (1): 123-142. https://doi.org/10.2478/fman-2018-0011.

Kumar, A. 2018. Methods and materials for smart manufacturing: Additive manufacturing, internet of things, flexible sensors and soft robotics. Manufacturing Letters 15: 122-125. https://doi.org/10.1016/j.mfglet.2017. 12.014 .

Lasi, H., P. Fettke, H.G. Kemper, T. Feld, and M. Hoffmann. 2014. Industry 4.0. Business \& Information Systems Engineering 6 (4): 239-242. https://doi. org/10.1007/s12599-014-0334-4.

Leminen, S., M. Rajahonka, M. Westerlund, and R. Wendelin. 2018. The future of the Internet of Things: Toward heterarchical ecosystems and service business models. Journal of Business \& Industrial Marketing 33 (6): 749-767. https://doi.org/10.1108/JBIM-10-2015-0206.

Matthyssens, P. 2019. Reconceptualizing value innovation for Industry 4.0 and the Industrial Internet of Things. Journal of Business \& Industrial Marketing 34 (6): 1203-1209. https://doi.org/10.1108/JBIM-11-2018-0348.

Mayring, P. 2015. Qualitative Inhaltsanalyse: Grundlagen und Techniken, 12th ed. Weinheim: Beltz.

Mills, S., S. Lucas, L. Irakliotis, M. Rappa, T. Carlson, and B. Perlowitz. 2012. Demystifying big data: A practical guide to transforming the business of government. Washington, DC: TechAmerica Foundation. 
Müller, J. M. 2019. Business model innovation in small-and medium-sized enterprises. Journal of Manufacturing Technology Management 30 (8), 11271142. https://doi.org/10.1108/JMTM-01-2018-0008.

Müller, J.M., and S. Däschle. 2018. Business model innovation of industry 4.0 solution providers towards customer process innovation. Processes 6 (12), 260. https://doi.org/10.3390/pr6120260.

Müller, J.M., O. Buliga, and K.-I. Voigt. 2018. Fortune favors the prepared: How SMEs approach business model innovations in Industry 4.0. Technological Forecasting and Social Change 132: 2-17. https://oi.org/10.1016/j. techfore.2017.12.019.

Müller, J.M., O. Buliga, and K.-I. Voigt. 2020. The role of absorptive capacity and innovation strategy in the design of industry 4.0 business ModelsA comparison between SMEs and large enterprises. European Management Journal. https://doi.org/10.1016/j.emj.2020.01.002.

Orzes, G., R. Poklemba, and W.T. Towner. 2020. Implementing Industry 4.0 in SMEs: A focus group study on organizational requirements. In Industry 4.0 for SMEs, ed. D.T. Matt, V. Modrák, and H. Zsifkovits, 251277. Cham: Palgrave Macmillan. https://doi.org/10.1007/978-3-030-254 25-4_9.

Osterwalder, A., Y. Pigneur, and C.L. Tucci. 2005. Clarifying business models: Origins, present, and future of the concept. Communications of the Association for Information Systems 16 (1), 1-25. https://doi.org/10.17705/1CAIS. 01601.

Osterwalder, A., and Y. Pigneur. 2010. Business model generation: A handbook for visionaries, game changers, and challengers. Hoboken: Wiley.

Pisano, P., M. Pironti, and A. Rieple. 2015. Identify innovative business models: can innovative business models enable players to react to ongoing or unpredictable trends? Entrepreneurship Research Journal 5 (3): 181-199. https://doi.org/10.1515/erj-2014-0032.

Porter, M.E., and J.E. Heppelmann. 2014. How smart, connected products are transforming competition. Harvard Business Review 99 (11): 64-88.

Rayna, T., and L. Striukova. 2016. From rapid prototyping to home fabrication: How 3D printing is changing business model innovation. Technological Forecasting and Social Change 102: 214-224. https://doi.org/10.1016/j.tec hfore.2015.07.023.

Rejikumar, G., V.R. Sreedharan, P. Arunprasad, J. Persis, and K.M. Sreeraj. 2019. Industry 4.0: Key findings and analysis from the literature arena. Benchmarking: An International Journal 26 (8): 2514-2542. https://doi.org/ 10.1108/BIJ-09-2018-0281. 
Rüssmann, M., M. Lorenz, P. Gerbert, M. Waldner, J. Justus, P. Engel, and M. Harnisch. 2015. Industry 4.0: The future of productivity and growth in manufacturing industries. Boston Consulting Group 9 (1): 54-89.

Sauer, P.C., and M. Hiete. 2020. Multi-stakeholder initiatives as social innovation for governance and practice: A review of responsible mining initiatives. Sustainability 12 (1): 236. https://doi.org/10.3390/su12010236.

Sauer, P.C., and S. Seuring. 2017. Sustainable supply chain management for minerals. Journal of Cleaner Production 151: 235-249. https://doi.org/10. 1016/j.jclepro.2017.03.049.

Schallmo, D., C.A. Williams, and L. Boardman. 2017. Digital transformation of business models-Best practice, enablers, and roadmap. International Journal of Innovation Management 21 (08): 1740014. https://doi.org/10. 1142/S136391961740014X.

Seuring, S., and S. Gold. 2012. Conducting content-analysis based literature reviews in supply chain management. Supply Chain Management: an International Journal 17 (5): 544-555. https://doi.org/10.1108/135985412112 58609.

Ślusarczyk, B. 2018. Industry 4.0: Are we ready? Polish Journal of Management Studies 17 (1): 232-248. http://dx.doi.org/10.17512\%2Fpjms.2018. 17.1.19.

Spieth, P., and S. Schneider. 2016. Business model innovativeness: designing a formative measure for business model innovation. Journal of Business Economics 86 (6): 671-696. https://doi.org/10.1007/s11573-015-0794-0.

Spieth, P., T. Röth, and S. Meissner. 2019. Reinventing a business model in industrial networks: Implications for customers' brand perceptions. Industrial Marketing Management 83: 275-287. https://doi.org/10.1016/j.indmar man.2019.04.013.

Strandhagen, J.O., L.R. Vallandingham, G. Fragapane, J.W. Strandhagen, A.B.H. Stangeland, and N. Sharma. 2017. Logistics 4.0 and emerging sustainable business models. Advances in Manufacturing 5 (4): 359-369. https://doi.org/10.1007/s40436-017-0198-1.

Teece, D.J. 2010. Business models, business strategy and innovation. Long Range Planning 43 (2-3): 172-194. https://doi.org/10.1016/j.lrp.2009. 07.003 .

Tirabeni, L., P. De Bernardi, C. Forliano, and M. Franco. 2019. How can organisations and business models lead to a more sustainable society? A framework from a systematic review of the industry 4.0. Sustainability 11 (22): 6363. https://doi.org/10.3390/su11226363. 
Tranfield, D., D. Denyer, and P. Smart. 2003. Towards a methodology for developing evidence-informed management knowledge by means of systematic review. British Journal of Management 14 (3): 207-222. https://doi.org/ 10.1111/1467-8551.00375.

Weking, J., M. Stöcker, M. Kowalkiewicz, M. Böhm, and H. Krcmar. 2019. Leveraging industry 4.0-A business model pattern framework. International Journal of Production Economics 225: 107588. https://doi.org/10.1016/j.ijpe. 2019.107588.

Zott, C., and R. Amit. 2010. Business model design: An activity system perspective. Long Range Planning 43 (2-3): 216-226. https://doi.org/10. 1016/j.lrp.2009.07.004.

Open Access This chapter is licensed under the terms of the Creative Commons Attribution 4.0 International License (http://creativecommons.org/ licenses/by/4.0/), which permits use, sharing, adaptation, distribution and reproduction in any medium or format, as long as you give appropriate credit to the original author(s) and the source, provide a link to the Creative Commons license and indicate if changes were made.

The images or other third party material in this chapter are included in the chapter's Creative Commons license, unless indicated otherwise in a credit line to the material. If material is not included in the chapter's Creative Commons license and your intended use is not permitted by statutory regulation or exceeds the permitted use, you will need to obtain permission directly from the copyright holder.

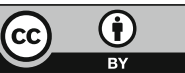

